\title{
ON THE ROLE OF EXTENSIONAL RHEOLOGY AND DEBORAH NUMBER ON THE NECK-IN PHENOMENON DURING FLAT FILM CASTING
}

\author{
Tomas Barborik $^{1}$, Martin Zatloukal ${ }^{1, *}$ and Costas Tzoganakis ${ }^{2}$ \\ ${ }^{1}$ Polymer Centre, Faculty of Technology, Tomas Bata University in Zlin, \\ Vavreckova 275, 76001 Zlin, Czech Republic \\ ${ }^{2}$ Department of Chemical Engineering, University of Waterloo, \\ 200 University Avenue West, Waterloo, Ontario, Canada
}

Keywords: Flat film production, polymer melt, rheology, neck-in phenomenon, uniaxial extensional viscosity, planar extensional viscosity.

*Corresponding author: mzatloukal@ft.utb.cz 


\begin{abstract}
In this work, viscoelastic, isothermal extrusion film casting simulations have been performed utilizing a 1D membrane model and the viscoelastic modified Leonov model as the constitutive equation in order to elucidate the role of planar to uniaxial extensional viscosity ratio, extensional strain hardening and Deborah number on the neck-in phenomenon. Based on the performed theoretical parametric study, it has been found that neck-in can be correlated to all the above mentioned variables via a simple dimensionless analytical equation. This correlation can provide detailed view into the complicated relationship between polymer melt rheology, die design, process conditions and undesirable neck-in phenomenon. Obtained results have been validated against literature experimental data for different polyethylene melts and processing conditions.
\end{abstract}




\section{INTRODUCTION}

Extrusion film casting (EFC) is a continuous, high-speed manufacturing process during which a thin, highly oriented polymer film is produced [1,2]. In this widely used and dominant process, a molten polymer is extruded through a slit die with a narrow gap to form a thick sheet of polymer that is subsequently intensively stretched in the machine direction by means of a rotating take-up drum, whose linear velocity is higher than the extrusion one, providing the macromolecular orientation and reduction in the sheet thickness and finally the dimensions of the created thin film are fixed by cooling down on a chill roll. The intensity of film drawing is usually measured by means of draw ratio defined as a linear velocity at the take-up drum divided by polymer exit velocity at the extrusion die.

In the section where the formation of the thin film takes place, i.e. within the drawing length, the cross-sectional dimensions of the sheet decreases monotonically as it travels towards the cooling stage (except in the swell region near the die exit). Under certain processing conditions, several phenomena may be encountered in this region, which hamper the required production in film quality and quantity. One of them is called neck-in causing an undesirable reduction in film width (see Figure 1) and interrelated phenomenon of edgebeads (also called dog-bone defect) making the edge portions of the film substantially thicker than its central part. Both of these steady state disruptions result in necessary post-production film trimming since only the central part of the film is uniform in thickness. From a practical viewpoint, it is of great importance, therefore, to understand the underlying mechanism of neck-in formation in order to minimize these unwanted effects. In addition, outside of the steady state processing window at high drawing rates, the transient disruption, called draw resonance, causing periodical variations in dimensions of the produced film as well as film brakeage itself may occur $[3,4]$. 
Polymer sheet or filament drawing has been studied extensively over the past four decades both experimentally and theoretically due to its great importance in the polymer processing industry. Initial efforts were made on a fiber spinning process for which the flow kinematics are similar from a mathematical point of view if considered as the onedimensional flow case, for Newtonian and Maxwell fluids by Gelder [5] and Fisher [6,7], respectively. Those studies were aimed on investigating the draw resonance phenomenon which was encountered for the first time by Christensen [8] and Miller [9], and who postulated that the nature of this phenomenon was not of viscoelastic nature because it could be observed in Newtonian fluids as well. Extending the process kinematics into two or three dimensions, the processes differ and one can observe phenomena in film casting that do not have a counterpart in fiber spinning, i.e. neck-in and edge-beading. The preliminary studies mentioned above provided the background for extended studies on EFC. Initial attempts to simulate EFC operations were dedicated to investigation of process stability and determination of draw resonance onset rather than to quantify the extent of neck-in phenomenon. The very first study on modeling of EFC process in this manner was carried out by Yeow [10] involving a Newtonian fluid with simplified kinematics based on the assumption of infinite film width under isothermal conditions. In other words, the width of the film was deemed as a constant so that the model did not account for either neck-in or edge-bead defect. Aird and Yeow [11] continued on this equation background of 1D model and extended analysis for power-law fluids, and then Anturkar and Co [12] and Iyengar and Co $[13,14]$ utilizing isothermal modified convected-Maxwell fluid and Giesekus constitutive equations for linear and non-linear analysis in simulations of viscoelastic fluids. First isothermal trials towards necking phenomena modeling were carried out by Sergent [15] and then by Cotto, Duffo and Barq [16-18] for non-isothermal conditions. 
Another milestone work has been set by Dobroth and Erwin [19] who pointed out that the deformation flow in the drawing length comprises of two related regions and the extent of edge-beads and interrelated neck-in phenomenon is determined by the interplay between them through an edge stress effect. While the center of the film undergoes planar elongational deformation, the edge sections are subjected to uniaxial elongational one (see Figure 2).

In the case of fiber spinning, however, one can observe uniaxial elongational flow only. Some authors endeavoured to relate and quantify the gauge of the observed necking in terms of rheological parameters, such as shear, uniaxial and planar viscosity. Many authors reported that the strain hardening in uniaxial elongational viscosity may depress the extent of necking phenomena [20-23]. This idea was continued by Ito [24], who related the neck-in extent to rheological parameters such as the ratio of planar viscosities in axial and transverse directions, and derived an analytical equation for the edge line of a molten film of Newtonian and Maxwell fluid. Along the line of Dobroth and Erwin's article [19], who as the first recognized deformation type in the drawing area, Shiromoto [25-27], recently, presented the idea that the extent of the necking should not have been described by uniaxial elongational viscosity only in addition to take-up length but as the ratio of planar and uniaxial elongational viscosities reflecting the deformation type in the central and edge portion of the film in the drawing section. Aside from performing non-isothermal viscoelastic simulations, they also proposed a theoretical model based on force balance and deformation type of a film in order to predict necking behavior.

More recently, a 2D membrane model was presented by d'Halewyu [28] and Debbaut [20] for Newtonian and viscoelastic fluids, respectively. This frequently used model was capable of predicting the dog-bone defect, i.e. development of edge-beads, under the stationary conditions. Silagy et al. [29] proceeded forward and enriched the membrane model by a supplementary kinematic hypothesis that was originally brought by 
Narayanaswamy [30] in his paper on float glass stretching, and carried out an extended isothermal study on the influence of processing conditions on film geometry, and stability analysis of EFC for Newtonian and Maxwell fluid using the UCM constitutive equation. Because of the assumptions used in flow kinematics, this model was able to cover film width reduction and thus predict the neck-in phenomenon but was still not able to predict edgebeading. This limitation was removed in their succeeding work [31] where the $2 \mathrm{D}$ isothermal membrane model combined with PTT constitutive equation was developed and obtained steady and transient stability results compared with its 1D predecessor. In the following years, the 1D version of Sylagy's membrane model was used in many studies and considerable amount of work has been done on EFC under non-isothermal conditions including crystallization effects by Lamberti et al. [32-35], Lamberti and Titomanlio [34,3638], and Lamberti [39]. A three dimensional model for EFC simulation was further developed by Sakaki et al. [40] and Zheng et al. [41] for isothermal and non-isothermal steady Newtonian fluid, respectively.

The influence of macromolecular architecture on the extent of necking phenomenon has been investigated by Ito et al. [24,42] (effects of draw ratio and take-up length on necking for LDPE, HDPE and mLLDPE) and Baird et al. [43,44] (effects of long chain branching and molecular weight distribution on necking for LDPE, mLLDPE and Ziegler-Natta catalyzed LLDPE). Recently, Pol et al. [45,46] and Chikhalikar et al. [47] have published a series of articles in which they have performed experimental and theoretical investigations of the effects of long chain branching and molecular weight distribution on the necking phenomenon extent. For this purpose, they utilized the 1D membrane model, originally proposed by Silagy [29], the multi-mode eXtended Pom-Pom constitutive equation and the multi-mode Rolie-Poly stretch constitutive equation, respectively, for the long chain branched (LDPE, PP) and the linear (HDPE, PP) polymers. Fixing the DR and TUL, they found that 
the extent of necking is lesser for HDPE with a broader molecular weight distribution than that for LLDPE with a narrower molecular weight distribution and further that long chain branched LDPE necks-in to lower extent than linear HDPE or LLDPE. In their latest work [48], they addressed the effects of the individual viscoelastic relaxation modes of a polymer melt on its behavior in polymer melt extrusion film casting process using UCM and PTT constitutive equations. They found that experimental data for long-chain branched LDPE was described better by UCM model, whereas PTT model provided better simulation results for the linear LLDPE experimental data.

Even though, the real EFC manufacturing process involves complex kinematics and is considered as a 3D problem whose numerical simulation can be very demanding, it has been proven by many authors that the EFC 1D membrane model originally proposed by Silagy [29], if used in combination with appropriate constitutive equations, is capable of providing results that are in good agreement with experiment data.

In the present work, a theoretical study of the neck-in phenomenon under steady-state isothermal conditions is carried out utilizing the 1D membrane model together with viscoelastic modified Leonov constitutive equations. The influence of uniaxial extensional strain hardening, planar to uniaxial extensional viscosity ratio and Deborah number is systematically studied and the results are compared with corresponding experimental data taken from the open literature.

\section{MATHEMATICAL MODELING}

\section{Modified Leonov Model}

This constitutive equation is based on heuristic thermodynamic arguments resulting from the theory of rubber elasticity [49-54]. In the model, fading memory of the melts is determined 
through an irreversible dissipation process driven by the dissipation term, $b$. Mathematically, it is relating the stress and elastic strain stored in the material as:

$$
\underset{=}{\tau}=2\left(\underline{\underline{\mathrm{c}}} \cdot \frac{\partial \mathrm{W}}{\partial \mathbf{I}_{1, \mathrm{c}}}-\underline{\mathrm{c}}^{-1} \cdot \frac{\partial \mathrm{W}}{\partial \mathbf{I}_{2, \mathrm{c}}}\right)
$$

where $\tau$ is the stress, and $W$, the elastic potential, which depends on the invariants $I_{1, c}$ and $I_{2, c}$ of the recoverable Finger tensor $\stackrel{c}{\underline{c}}$,

$$
\mathrm{W}=\frac{3 \mathrm{G}}{2(\mathrm{n}+1)}\left\{[1-\beta] \cdot\left[\left(\frac{\mathrm{I}_{1, \mathrm{c}}}{3}\right)^{\mathrm{n}+1}-1\right]+\beta\left[\left(\frac{\mathrm{I}_{2, \mathrm{c}}}{3}\right)^{\mathrm{n}+1}-1\right]\right\}
$$

where $G$ denotes linear Hookean elastic modulus, $\beta$ and $n$ are numerical parameters. Leonov assumed that the dissipative process acts to produce an irreversible rate of strain $e_{p}$

$$
\stackrel{\mathrm{e}}{\mathrm{p}}_{\mathrm{p}}=\mathrm{b}\left[\underline{\underline{\mathrm{c}}}-\frac{\mathrm{I}_{1, \mathrm{c}}}{3} \underline{\underline{\delta}}\right]-\mathrm{b}\left[\underline{\underline{c}}^{-1}-\frac{\mathrm{I}_{2, \mathrm{c}}}{3} \underline{\underline{\delta}}\right]
$$

which spontaneously reduces the rate of elastic strain accumulation. Here, $\underline{\underline{\delta}}$ is the unit tensor and $b$ stands for dissipation function defined by Eq. 5. This elastic strain $\underline{\underline{c}}$ is related to the deformation rate tensor $\underline{\underline{\mathrm{D}}}$ as follows

$$
\underline{\underline{\mathrm{c}}}-\underline{\underline{\mathrm{c}}} \cdot \underline{\underline{\mathrm{D}}}-\underline{\underline{\mathrm{D}}} \cdot \underline{\underline{\mathrm{c}}}+2 \underline{\underline{\mathrm{c}}} \cdot \underline{\underline{\mathrm{e}}} \mathrm{p}=0
$$

where $\underline{\underline{c}}$ is the Jaumann (corotational) time derivative of the recoverable Finger strain tensor. In this work, the Mooney potential (i.e. $n=0$ in Eq. 2), and the dissipation function $b$ proposed in [55] (see Eq. 5) have been employed.

$$
\mathrm{b}\left(\mathrm{I}_{1, \mathrm{c}}\right)=\frac{1}{4 \lambda}\left\{\exp \left[-\xi \sqrt{\mathrm{I}_{1, \mathrm{c}}-3}\right]+\frac{\sinh \left[v\left(\mathrm{I}_{1, \mathrm{c}}-3\right)\right]}{v\left(\mathrm{I}_{1, \mathrm{c}}-3\right)+1}\right\}
$$

Here, $\xi$ and $v$ are adjustable model parameters.

$$
\mathrm{I}_{1, \mathrm{c}}=\operatorname{tr}(\underline{\underline{\mathrm{c}}})
$$




$$
\begin{aligned}
& \operatorname{tr}(\underline{\underline{\mathrm{c}}})=\mathrm{c}_{\mathrm{xx}}+\mathrm{c}_{\mathrm{yy}}+\mathrm{c}_{\mathrm{zz}} \\
& \mathrm{I}_{2, \mathrm{c}}=\frac{1}{2}\left\{[\operatorname{tr}(\underline{\underline{\mathrm{c}}})]^{2}-\operatorname{tr}\left({\underline{\underline{\mathrm{c}^{2}}}}^{2}\right)\right\} \\
& \mathrm{I}_{2, \mathrm{c}}=\mathrm{c}_{\mathrm{xx}}^{-1}+\mathrm{c}_{\mathrm{yy}}^{-1}+\mathrm{c}_{\mathrm{zz}}^{-1}
\end{aligned}
$$

Differentiating Eq. 2 with respect to the first and second invariant of the recoverable Finger tensor yields

$$
\begin{aligned}
& \frac{\partial \mathrm{W}}{\partial \mathrm{I}_{1, \mathrm{c}}}=\frac{1}{2} \mathrm{G}\left(\frac{\mathrm{I}_{1, \mathrm{c}}}{3}\right)^{\mathrm{n}}(1-\beta) \\
& \frac{\partial \mathrm{W}}{\partial \mathrm{I}_{2, \mathrm{c}}}=\frac{1}{2} \mathrm{G} \beta\left(\frac{\mathrm{I}_{2, \mathrm{c}}}{3}\right)^{\mathrm{n}}
\end{aligned}
$$

Combination of Eq. 1 with Eqs. 10-11 leads to the following expression for the extra stress tensor.

$$
\stackrel{\tau}{=}=\mathrm{G}\left\{\underline{\mathrm{c}}=\left[\left(\frac{\mathrm{I}_{1, \mathrm{c}}}{3}\right)^{\mathrm{n}}(1-\beta)\right]-\underline{\mathrm{c}}^{-1}\left[\beta\left(\frac{\mathrm{I}_{2, \mathrm{c}}}{3}\right)^{\mathrm{n}}\right]\right\}
$$

\section{Extrusion Film Casting Model}

In this work, the one-dimensional membrane model developed by Silagy et al. [29] was used to model the isothermal extrusion film casting process (see Figure 3). The model essentially features two hypotheses to facilitate the description of the stress and velocity field development in the film drawing. Firstly, the total stress in the film thickness direction is assumed to be equal to zero because this dimension is small compared to other dimensions and secondly, velocities in the width and thickness direction are allowed to vary linearly with $\mathrm{y}$ and $\mathrm{z}$ position, respectively, for the given $\mathrm{x}$ location, which represents a supplementary kinematic hypothesis (formerly adopted in the work of Narayanaswamy [30] for the modeling of glass manufacturing by the float process) in order to reduce the dimensionality of the task. 
As a result, all model variables are x-direction dependent only and the model can be considered as one-dimensional although lateral film width and thickness reduction can be modeled. Furthermore, the inertia, gravity, surface tension and aerodynamic drag are neglected in this model because they are usually much smaller in comparison with the stresses generated in the viscoelastic polymer melt. Finally, the process is treated here as an isothermal one, which can be justifiable for small enough drawing lengths and/or very high draw-down speeds [56]. The detailed description of the utilized model is provided below.

\section{Velocity field}

The Cartesian system axes are directed as follows (see Fig. 3): in-film-plane axes $\mathrm{x}$ and $\mathrm{y}$, where $\mathrm{x}$ points in the streamwise direction and $\mathrm{y}$ is perpendicular onto it, and $\mathrm{z}$ axis is normal to the film xy plane with origin deployment in the cross-sectional center of gravity at the die exit. The dimensions of the film are denoted as follows: take up length is $X$, initial film half-width is $L_{0}$, and initial half-thickness is $e_{0}$. The intensity of film drawing is expressed in terms of draw ratio (DR) that relates the final tangential velocity of the film at the chill roll, $u(X)$, to the film velocity at the die exit, $u_{0}$. The quantities without a zero subscript denotes non-initial corresponding dimensions at any given $\mathrm{x}$ position. The influence of extrudate swelling on the casting process is assumed to be negligible here. Using the symmetry of the problem and the kinematic hypothesis, the complexity of the velocity field involved in the

film drawing is reduced, where each of the components is the function of all spatial and time variables. In the resulting form, the velocity field for steady solution is approximated as follows:

$$
\begin{aligned}
& \mathrm{u}=\mathrm{u}(\mathrm{x}) \\
& \mathrm{v}=\mathrm{v}(\mathrm{x}, \mathrm{y})=\mathrm{yf}(\mathrm{x}) \\
& \mathrm{w}=\mathrm{w}(\mathrm{x}, \mathrm{z})=\mathrm{zg}(\mathrm{x})
\end{aligned}
$$


where $u, v$ and $w$ are the velocity components in the machine, transverse, and thickness direction, respectively. The deformation rate tensor, which is based on Eq. 13, takes the following form:

$$
\underline{D}=\left[\begin{array}{ccc}
\frac{\mathrm{du}}{\mathrm{dx}} & \frac{1}{2} \mathrm{y} \frac{\mathrm{df}}{\mathrm{dx}} & \frac{1}{2} \mathrm{z} \frac{\mathrm{dg}}{\mathrm{dx}} \\
\frac{1}{2} \mathrm{y} \frac{\mathrm{df}}{\mathrm{dx}} & \mathrm{f}(\mathrm{x}) & 0 \\
\frac{1}{2} \mathrm{z} \frac{\mathrm{dg}}{\mathrm{dx}} & 0 & \mathrm{~g}(\mathrm{x})
\end{array}\right]
$$

Since the polymer flow in EFC is mainly extensional and in an effort to increase simplicity, the shear rate components can be neglected in favour of elongational ones in Eq. 14, which leads to the following final expression for the deformation rate tensor:

$$
\underline{D}=\left[\begin{array}{ccc}
\frac{d u}{d x} & 0 & 0 \\
0 & f(x) & 0 \\
0 & 0 & g(x)
\end{array}\right]
$$

The film thickness is constant throughout the film width due to the assumed velocity field, where the $v$ and $w$ velocity components are dependent on $\mathrm{x}$ variable only and are allowed to vary linearly over the film width and thickness, respectively, due to the applied Narayanaswamy's supplementary kinematic hypothesis as mentioned above.

\section{Continuity equation}

The continuity equation requires the conservation of mass at any given streamwise position and with the incompressibility hypothesis takes the following form.

$$
\frac{\mathrm{d}}{\mathrm{dt}}(\mathrm{eL})+\frac{\mathrm{d}}{\mathrm{dx}}(\mathrm{eLu})=0
$$


Since the transient solution of the equation is not an objective of this study, the derivative with respect to time can be neglected. For steady state solution, the derivative with respect to time is

$$
\frac{\mathrm{d}}{\mathrm{dt}}(\mathrm{eL})=0
$$

and thus, the volumetric flow rate at the die exit position and at any given streamwise position is given by Eq. 18 and Eq. 19, respectively.

$$
\begin{aligned}
& \mathrm{e}_{0} \mathrm{~L}_{0} \mathrm{u}_{0}=\mathrm{Q} \\
& \mathrm{e}(\mathrm{x}) \mathrm{L}(\mathrm{x}) \mathrm{u}(\mathrm{x})=\mathrm{Q}
\end{aligned}
$$

It is important to mention that the volumetric flow rate $Q$ here corresponds to $1 / 4^{\text {th }}$ of the cross-section only due to the process symmetry as show in [57].

\section{Momentum conservation equation}

Considering the membrane approximation for the thin film in the presence of a constant drawing force, the stresses are constant over the cross section of the film, which leads to the force balance having the following form

$$
\frac{\mathrm{d}}{\mathrm{x}}\left(\sigma_{\mathrm{xx}} L \mathrm{Le}\right)=\frac{\mathrm{dF}}{\mathrm{dx}}=0
$$

Neglecting gravity, inertia, aerodynamic friction and surface tension forces, the drawing force becomes $\mathrm{x}$-direction independent, which is fully balanced by the stresses generated in the film.

$$
\mathrm{F}=\mathrm{const}=\sigma_{\mathrm{xx}} \mathrm{Le}
$$

In this equation, $\sigma_{\mathrm{xx}}$ stands for the first diagonal component of the total stress tensor, $\underline{\underline{\sigma}}$, which is defined via the extra stress tensor, $\tau$, as follows 


$$
\underset{=}{\sigma}=-p \underset{=}{\delta}+\underset{=}{=}=\left[\begin{array}{ccc}
-p+\tau_{x x} & 0 & 0 \\
0 & -p+\tau_{y y} & 0 \\
0 & 0 & -p+\tau_{z z}
\end{array}\right]
$$

where $p$ stands for the isotropic pressure, $\underset{\underline{\delta}}{\text { is }}$ the unity tensor. As it can be seen from Eq. 22, the diagonal components of the total stress tensor are defined as

$$
\begin{aligned}
& \sigma_{x x}=-p+\tau_{x x} \\
& \sigma_{y y}=-p+\tau_{y y} \\
& \sigma_{z z}=-p+\tau_{z z}
\end{aligned}
$$

The membrane approximation requires zero value of the thickness-wise component of total stress tensor, $\sigma_{\mathrm{zz}}=0$, which leads to

$$
0=-\mathrm{p}+\tau_{\mathrm{zz}}
$$

i.e.

$$
\tau_{\mathrm{zz}}=\mathrm{p}
$$

Substituting Eq. 25 back into expression for stress components Eq. 23, the hydrostatic pressure term is eliminated, which leads to the following final expression for the diagonal components of the total stress tensor

$$
\begin{aligned}
& \sigma_{\mathrm{xx}}=\tau_{\mathrm{xx}}-\tau_{\mathrm{zz}} \\
& \sigma_{\mathrm{yy}}=\tau_{\mathrm{yy}}-\tau_{\mathrm{zz}} \\
& \sigma_{\mathrm{zz}}=0
\end{aligned}
$$

After substitution of $\sigma_{\mathrm{xx}}$, which is given by Eq. 26, into Eq. 21, the final form of the force balance equation is obtained

$$
\left(\tau_{\mathrm{xx}}-\tau_{\mathrm{zz}}\right) \mathrm{Le}=\mathrm{F}
$$




\section{$\underline{\text { The stress-free surface boundary condition }}$}

Assuming the surface tension and air drag are negligible, the net force per unit surface at the film free surface is equal to zero:

$$
\underline{\sigma} \cdot \underline{\mathrm{n}}=0
$$

where the $\underline{n}$ is the unit vector normal to the free film surface. This yields the following expression relating the stress state of the film with the film half-width at given x position:

$$
\left(\frac{\mathrm{dL}}{\mathrm{dx}}\right)^{2}=\frac{\sigma_{\mathrm{yy}}}{\sigma_{\mathrm{xx}}}
$$

\section{The kinematic free-surface boundary condition}

The fluid is enclosed in the boundaries of the free surface, which can be expressed as

$$
\underline{\mathrm{u}} \cdot \underline{\mathrm{n}}=0
$$

where $\underline{u}$ is the tangential velocity at the film-air interface. Combination of Eq. 30 with the equation of continuity leads to

$$
\begin{aligned}
& u(x) \frac{d L}{d x}-f(x) L=0 \\
& u(x) \frac{d e}{d x}-g(x) e=0
\end{aligned}
$$

where $\mathrm{f}(\mathrm{x})$ and $\mathrm{g}(\mathrm{x})$ are components of the deformation rate tensor (see Eq. 15) in the width and thickness direction, respectively, which can simply be expressed as

$$
\begin{aligned}
& f(x)=\frac{u(x)}{L} \frac{d L}{d x} \\
& g(x)=\frac{u(x)}{e} \frac{d e}{d x}
\end{aligned}
$$

\section{$\underline{\text { Dimensionless transformation }}$}

For the sake of simplicity and scaling purposes, the dimensionless transformation has been introduced into the previously derived equations (having similar form as in [29]). 
Corresponding dimensionless quantities are denoted here with the overline symbol. Dimensionless transformation for the extra stress tensor and total stress tensor is defined here as

$$
\begin{gathered}
\bar{\tau}_{\mathrm{ii}}=\frac{\tau_{\mathrm{ii}} \mathrm{e}_{0} \mathrm{~L}_{0}}{\mathrm{~F}} \\
\bar{\sigma}_{\mathrm{ii}}=\frac{\sigma_{\mathrm{ii}} \mathrm{e}_{0} \mathrm{~L}_{0}}{\mathrm{~F}}
\end{gathered}
$$

whereas the dimensionless spatial dimensions and streamwise velocity component are

$$
\begin{aligned}
& \overline{\mathrm{x}}=\frac{\mathrm{x}}{\mathrm{X}} \\
& \overline{\mathrm{e}}=\frac{\mathrm{e}}{\mathrm{e}_{0}} \\
& \overline{\mathrm{L}}=\frac{\mathrm{L}}{\mathrm{L}_{0}} \\
& \overline{\mathrm{u}}=\frac{\mathrm{u}}{\mathrm{u}_{0}}
\end{aligned}
$$

Dimensionless numbers such as draw ratio, $D R$, Deborah number, $D e$, aspect ratio, $A$ and dimensionless force, $E$, are defined as follows

$$
\begin{aligned}
& \mathrm{DR}=\frac{\mathrm{u}(\mathrm{X})}{\mathrm{u}_{0}} \\
& \mathrm{De}=\frac{\lambda \mathrm{u}_{0}}{\mathrm{X}} \\
& \mathrm{A}=\frac{\mathrm{X}}{\mathrm{L}_{0}} \\
& \frac{1}{\mathrm{E}}=\frac{\mathrm{FX}}{\mathrm{G} \lambda \mathrm{e}_{0} \mathrm{~L}_{0} \mathrm{u}_{0}}
\end{aligned}
$$


Introducing the dimensionless transformation into the continuity equation (Eq. 19) and momentum conservation equation (Eq. 27) leads to the following dimensionless implicit forms

$$
\begin{aligned}
& \overline{\mathrm{e}} \overline{\mathrm{L}} \overline{\mathrm{u}}=1 \\
& \left(\bar{\tau}_{\mathrm{xx}}-\bar{\tau}_{\mathrm{zz}}\right) \overline{\mathrm{L}} \overline{\mathrm{e}}=1
\end{aligned}
$$

Substitution of Eq. 45 into Eq. 46 gives

$$
\left(\bar{\tau}_{\mathrm{xx}}-\bar{\tau}_{\mathrm{zz}}\right)-\overline{\mathrm{u}}=0
$$

and differentiating Eq. 45 and Eq. 47 with respect to $\mathrm{x}$ variable, one can obtain

$$
\begin{aligned}
& \frac{1}{\overline{\mathrm{e}}} \frac{\mathrm{d} \overline{\mathrm{e}}}{\mathrm{d} \overline{\mathrm{x}}}+\frac{1}{\overline{\mathrm{L}}} \frac{\mathrm{d} \overline{\mathrm{L}}}{\mathrm{d} \overline{\mathrm{x}}}+\frac{1}{\overline{\mathrm{u}}} \frac{\mathrm{d} \overline{\mathrm{u}}}{\mathrm{d} \overline{\mathrm{x}}}=0 \\
& \frac{\bar{\tau}_{\mathrm{xx}}}{\mathrm{d} \overline{\mathrm{x}}}-\frac{\bar{\tau}_{\mathrm{zz}}}{\mathrm{d} \overline{\mathrm{x}}}-\frac{\mathrm{d} \overline{\mathrm{u}}}{\mathrm{d} \overline{\mathrm{x}}}=0
\end{aligned}
$$

After rearrangement, the derivative of the dimensionless film half-thickness and axial velocity with respect to $\mathrm{x}$ are finally defined as

$$
\begin{aligned}
& \frac{d \bar{e}}{d \bar{x}}=-\left(\frac{1}{\bar{L}} \frac{d \bar{L}}{d \bar{x}}+\frac{1}{\bar{u}} \frac{d \bar{u}}{d \bar{x}}\right) \bar{e} \\
& \frac{d \bar{u}}{d \bar{x}}=\frac{d \bar{\tau}_{x x}}{d \bar{x}}-\frac{d \bar{\tau}_{z z}}{d \bar{x}}
\end{aligned}
$$

The dimensionless forms for $f(x)$ and $g(x)$ functions, which were derived from the kinematic free-surface boundary condition and appear in the deformation rate tensor, are the following

$$
\begin{aligned}
& \bar{f}=\frac{L_{0}}{u_{0}} f(x) \\
& \bar{g}=\frac{e_{0}}{u_{0}} g(x)
\end{aligned}
$$

Finally, the dimensionless transformation for the x-direction derivative of the film half-width (arising from Eq. 26 and Eq. 29) yields 


$$
\frac{\mathrm{d} \overline{\mathrm{L}}}{\mathrm{d} \overline{\mathrm{x}}}=-\mathrm{A} \sqrt{\frac{\bar{\tau}_{\mathrm{yy}}-\bar{\tau}_{\mathrm{zz}}}{\bar{\tau}_{\mathrm{xx}}-\bar{\tau}_{\mathrm{zz}}}}
$$

\section{Extrusion film casting model for the modified Leonov model}

In order to combine the modified Leonov constitutive equation and the extrusion film casting model equations, it is necessary to derive the equation for particular stress development along the $\mathrm{x}$ axis. The relationship between the dimensionless stress and the recoverable strain, imposed from the modified Leonov model (Eqs. 1 and 12), can be described by the following formula (for the case of the Mooney potential, i.e. when $n=0$ and $\beta \neq 0$ ):

$$
\bar{\tau}_{\mathrm{ii}}=\frac{\mathrm{E}}{\mathrm{De}} \mathrm{c}_{\mathrm{ii}}-\frac{\mathrm{E}}{\mathrm{De}} \mathrm{c}_{\mathrm{ii}} \cdot \beta-\frac{\mathrm{E}}{\mathrm{De}} \mathrm{c}_{\mathrm{ii}}^{-1} \cdot \beta
$$

Differentiating this equation with respect to $x$ leads to

$$
\frac{\mathrm{d} \bar{\tau}_{\mathrm{ii}}}{\mathrm{d} \overline{\mathrm{x}}}=\frac{\mathrm{E}}{\mathrm{De}} \frac{\mathrm{dc}_{\mathrm{ii}}}{\mathrm{d} \overline{\mathrm{x}}}-\frac{\mathrm{E}}{\mathrm{De}} \beta \frac{\mathrm{dc}_{\mathrm{ii}}}{\mathrm{d} \overline{\mathrm{x}}}-\frac{\mathrm{E}}{\operatorname{De}} \beta\left(-\frac{1}{\mathrm{c}_{\mathrm{ii}}^{2}} \frac{\mathrm{dc}_{\mathrm{ii}}}{\mathrm{d} \overline{\mathrm{x}}}\right)
$$

where $\frac{d c_{i i}}{d \bar{x}}$ stands for the $\mathrm{x}$-direction derivative of the recoverable strain tensor. This term is defined by Eq. 4 and for each component of the recoverable strain tensor it takes the following form:

$$
\begin{aligned}
& \frac{d c_{x x}}{d \bar{x}}=2 c_{x x} \frac{1}{\bar{u}} \frac{d \bar{u}}{d \bar{x}}-\frac{2 \bar{b}}{\bar{u}} Z_{x} \\
& \frac{d c_{y y}}{d \bar{x}}=2 c_{y y} \frac{1}{\bar{L}} \frac{d \bar{L}}{d \bar{x}}-\frac{2 \bar{b}}{\bar{u}} Z_{y} \\
& \frac{d c_{z z}}{d \bar{x}}=2 c_{z z} \frac{1}{\bar{e}} \frac{d \bar{e}}{d \bar{x}}-\frac{2 \bar{b}}{\bar{u}} Z_{z}
\end{aligned}
$$

where $\bar{b}, Z_{i}$ and $X_{p}$ are defined as

$$
\bar{b}\left(I_{1, c}\right)=\frac{1}{4 \operatorname{De}}\left\{\exp \left[-\xi \sqrt{I_{1, c}-3}\right]+\frac{\sinh \left[v\left(I_{1, \mathrm{c}}-3\right)\right]}{v\left(I_{1, \mathrm{c}}-3\right)+1}\right\}
$$




$$
\begin{aligned}
& Z_{\mathrm{i}}=\mathrm{c}_{\mathrm{ii}}\left(\mathrm{c}_{\mathrm{ii}}-\mathrm{c}_{\mathrm{ii}}^{-1}+\mathrm{X}_{\mathrm{p}}\right) \\
& \mathrm{X}_{\mathrm{p}}=\frac{1}{3}\left(\mathrm{c}_{\mathrm{xx}}^{-1}+\mathrm{c}_{\mathrm{yy}}^{-1}+\mathrm{c}_{\mathrm{zz}}^{-1}-\mathrm{c}_{\mathrm{xx}}-\mathrm{c}_{\mathrm{yy}}-\mathrm{c}_{\mathrm{zz}}\right)
\end{aligned}
$$

Combination of Eq. 51 and Eq. 56 leads to the dimensionless streamwise deformation rate, which takes the following form

$$
\frac{\mathrm{d} \overline{\mathrm{u}}}{\mathrm{d} \overline{\mathrm{x}}}=\frac{\overline{\mathrm{b}}\left[\beta\left(\mathrm{Z}_{\mathrm{x}}-\mathrm{Z}_{\mathrm{z}}\right)-\mathrm{Z}_{\mathrm{x}}+\mathrm{Z}_{\mathrm{z}}\right]+\overline{\mathrm{b}} \beta\left(\frac{1}{\mathrm{c}_{\mathrm{zz}}^{2}} \mathrm{Z}_{\mathrm{z}}-\frac{1}{\mathrm{c}_{\mathrm{xx}}^{2}} \mathrm{Z}_{\mathrm{x}}\right)+\frac{\overline{\mathrm{u}}}{\overline{\mathrm{L}}} \frac{\mathrm{d} \overline{\mathrm{L}}}{\mathrm{d} \overline{\mathrm{x}}}\left(\mathrm{c}_{\mathrm{zz}}(1-\beta)+\frac{\beta}{\mathrm{c}_{\mathrm{zz}}}\right)}{\beta\left(\mathrm{c}_{\mathrm{xx}}+\mathrm{c}_{\mathrm{zz}}\right)-\mathrm{c}_{\mathrm{xx}}-\mathrm{c}_{\mathrm{zz}}-\frac{\beta}{\mathrm{c}_{\mathrm{xx}}}\left(\frac{\mathrm{c}_{\mathrm{zz}}+\mathrm{c}_{\mathrm{xx}}}{\mathrm{c}_{\mathrm{zz}}}\right)+\frac{D e \overline{\mathrm{u}}}{2 \mathrm{E}}}
$$

\section{Boundary conditions}

The complex and essential explicit model equations constituted in the previous section, namely Eqs. 50, 54, 63, 57, 58, 59 has to be solved with the appropriate set of the boundary conditions. Detailed description of the utilized boundary conditions is provided below.

\section{Upstream boundary conditions:}

Taking advantage of the dimensionless transformation, the initial half-width, half-thickness, and streamwise velocity are equal to one.

$$
\begin{aligned}
& \overline{\mathrm{u}}(0)=1 \\
& \overline{\mathrm{e}}(0)=1 \\
& \overline{\mathrm{L}}(0)=1
\end{aligned}
$$

Since a viscoelastic constitutive equation is involved in this study, it is necessary to define initial boundary conditions for all three diagonal components of the extra stress tensor $\bar{\tau}_{\mathrm{xx}}(0)$, $\bar{\tau}_{\mathrm{yy}}(0)$ and $\bar{\tau}_{\mathrm{zz}}(0)$ by using Eq. 55 . To do that, diagonal components of the recoverable strain tensor at the die exit must be determined as the first by solving the following set of equations 


$$
\begin{aligned}
& \frac{E}{D e}\left[\left(c_{x x}-c_{z z}\right)(1-\beta)+\beta\left(c_{z z}^{-1}-c_{x x}^{-1}\right)\right]-1=0 \\
& c_{x x} c_{y y} c_{z z}=1 \\
& \frac{N_{2}}{N_{1}}=-\frac{E\left[c_{z z}-c_{y y}+\beta\left(c_{y y}+c_{y y}^{-1}-c_{z z}-c_{z z}^{-1}\right)\right]}{D e \bar{u}}
\end{aligned}
$$

Eq. 67 comes from the combination of Eqs. 47, 55 and 64 whereas Eq. 68 represents the incompressibility condition for the given flow situation. Eq. 69 represents normal stress difference ratio at the die exit, which is defined as the ratio of the secondary normal stress difference and primary normal stress difference

$$
\frac{\mathrm{N}_{2}}{\mathrm{~N}_{1}}=\frac{\bar{\tau}_{\mathrm{zz}}(0)-\bar{\tau}_{\mathrm{yy}}(0)}{\bar{\tau}_{\mathrm{xx}}(0)-\bar{\tau}_{\mathrm{zz}}(0)}
$$

Note, that in this equation $\bar{\tau}_{\mathrm{xx}}(0)-\bar{\tau}_{\mathrm{zz}}(0)=1$ as the result of Eq. 47 and Eq. 64. As it can clearly be seen from Eq. 69 , the $\mathrm{N}_{2} / \mathrm{N}_{1}$ ratio, which characterizes the polymer melt stress state at the die exit region, has to be provided in order to calculate the initial boundary conditions for the extra stress tensor.

\section{Downstream boundary conditions:}

Downstream boundary condition, draw ratio, is prescribed as the desired value that is satisfied by a priori unknown magnitude of the drawing force.

$$
\overline{\mathrm{u}}(\mathrm{X})=\mathrm{DR}
$$

\section{Numerical scheme}

The whole system of the first-order ordinary differential equations (namely Eqs. 50, 54, 63 for film half-thickness, half-width and velocity as well as Eqs. 57-59 for the components of the recoverable elastic strain tensor $c_{x x}, c_{y y}$ and $c_{z z}$ ) was numerically solved by the $4^{\text {th }}$ order Runge-Kutta algorithm with adaptive step-size control. For the given take-up force value, it 
was necessary to determine the components of the recoverable elastic strain tensor in order to satisfy Eqs. 50, 54 and 63 along with the other boundary conditions for the die exit region, that are constant with the force, and thus do not require evaluation in every iteration (Eqs. 64, 65,66 and $\mathrm{N}_{2} / \mathrm{N}_{1}$ ratio). The value of the force was guessed for the first iteration and then increased or decreased throughout foregoing iterations in order to meet the DR boundary condition (convergence) by Newton-Raphson method. It was preferred to develop the solver itself in the $\mathrm{C}++$ programming language, to avoid a black box effect, which could have appeared in the case of using a built-in solver in any other commercial mathematicalmodeling software. The equation evaluation was performed on the PC with the following hardware parameters: CPU Intel Core 2 Quad Q9650 (3.00 GHz), RAM 8 GB DDR2, GPU Sapphire Radeon HD 3870, SSD Crucial 256 GB. Typical computational time for one calculation was 2 minutes. A schematic representation of the utilized numerical scheme is provided in Figure 4.

\section{RESULTS AND DISCUSSION}

\section{Film Casting Model Validation}

In order to validate the utilized film casting model, we have used recent experimental and theoretical data provided in $[45,46,48]$ for very well characterized LDPE 170 A polymer (produced by The Dow Chemical Company, Freeport, TX, USA) having a flow activation energy $54 \mathrm{~kJ} / \mathrm{mol}$ and molecular characteristics, which are provided in Table 1.

In this work, the single-mode modified Leonov model was utilized to simplify the calculation. The model parameters were identified by using deformation rate dependent 'steady state' uniaxial extensional viscosity experimental data taken from Fig. 2b in [46] (i.e. from the peaks appearing on the transient extensional viscosity curves for corresponding extensional strain rates). Obtained model parameters are provided in Tab. 2. Interestingly, the 
measured data can be represented by the single-mode modified Leonov model very well as shown in Fig. 5a).

Modeled processing conditions for the film casting process were the same as described in [45,46], i.e. isothermal, die width $=100 \mathrm{~mm}$, gap size $=0.46 \mathrm{~mm}$, melt exit velocity $=4.3 \mathrm{~mm} / \mathrm{s}$, and distance between the die and roll $230 \mathrm{~mm}$. As it has already been mentioned, in the fully viscoelastic calculation based on the modified Leonov model, it is necessary to define the stress state at the end of the extrusion die, namely the ratio of the second normal stress difference, $N_{2}$, and first normal stress difference, $N_{1}$, which is given by the flow history inside the flat extrusion die. However, this rheological characteristic is not available for the given LDPE $170 \mathrm{~A}$ from $[45,46,48]$ and thus typical $-\mathrm{N}_{2} / \mathrm{N}_{1}=0.2$ value was taken from the open literature [58] to define the stress boundary condition at the die exit. Comparison between the film casting model predictions based on the single-mode modified Leonov model (this work), multi-mode XPP model and the corresponding experimental data (both taken from $[45,46]$ ) is provided in Fig. 5b-5d and Fig. 6. In Fig. 5b-5d, the basic dimensionless variables such as film half-width, half-thickness and center-line velocity are provided as the function of dimensionless distance between the die $(\overline{\mathrm{x}}=0)$ and the chill roll ( $\overline{\mathrm{x}}=1)$ for high draw ratio $(\mathrm{DR}=16)$ and Deborah number $(\mathrm{De}=0.011)$ whereas Figure 6 shows the effect of draw ratio on dimensionless final film half-width for low (0.011) and high (0.253) Deborah numbers. As it can be seen, the behavior of both models is comparable and the agreement with the experimental data is good for the given range of draw ratios and Deborah numbers. Such a reasonably good agreement with the experimental data justifies to use of the given film casting model with all applied assumptions together with even singlemode Leonov model for detailed parametric study of the neck-in phenomenon. In order to understand the undesired neck-in phenomenon in more detail, the role of Deborah number 
and extensional rheology was systematically investigated via a theoretical parametric study, which is described in the next section. 


\section{Theoretical analysis of neck-in phenomenon}

\section{The role of extensional rheology}

With the aim to understand the role of extensional behaviour of polymer melts on the neck-in phenomenon, 3 groups of virtual materials were generated with high, middle and low level of uniaxial extensional strain hardening defined as

$$
\frac{\eta_{\mathrm{E}, \mathrm{U}, \max }}{3 \eta_{0}}
$$

Here, $\eta_{E, U, \max }$ represents the maximum value in the steady uniaxial extensional viscosity and $\eta_{0}$ is the Newtonian viscosity. In each group, 5 virtual materials were generated having the same level of uniaxial extensional strain hardening but different level of planar extensional strain hardening defined as

$$
\frac{\eta_{\mathrm{E}, \mathrm{P}, \max }}{4 \eta_{0}}
$$

where $\eta_{E, P, \max }$ represents the maximum value in the steady planar extensional viscosity. Modified Leonov model parameters for the 15 utilized virtual polymer melts (one of them, Melt3_Middle, has identical parameters as the LDPE 170A melt described in Model validation section) are provided in Table 3 whereas their extensional rheology is provided in Figure 7.

The title of each virtual melt contains information about the level of uniaxial extensional strain hardening (Low, Middle, and High) as well as about the level of planar extensional strain hardening ( 1 - the lowest, $2,3,4$, and 5 - the highest). For example, the virtual samples entitled here as Melt1_High and Melt5_High means that both samples have different planar extensional strain hardening (i.e. the lowest in the first case and the highest in 
the second case) whereas their uniaxial extensional strain hardening is identical (high). Similarly, the virtual samples entitled as Melt1_High and Melt1_Low means that both samples have identical (the lowest) planar extensional strain hardening but different uniaxial extensional strain hardening (i.e. high and low in the first and second case, respectively). Each group of virtual materials (having the given level of uniaxial extensional strain hardening) can be then characterized by steady-state planar to uniaxial extensional viscosity ratio, $\frac{\eta_{E, P}}{\eta_{E, U}}$, plotted as the function of extensional strain rate, as visualized on the left side of Figure 8.

In the next step, the dimensionless final film half-width as the function of draw ratio was calculated for all 15 virtual polymer melts by using the film casting model keeping the Deborah number and $-\mathrm{N}_{2} / \mathrm{N}_{1}$ ratio the same, equal to 0.07 and 0.2 , respectively. Results are depicted on the right side of Figure 8. As it can be seen, if $\frac{\eta_{E, P}}{\eta_{E, U}}$ increases or $\frac{\eta_{E, U, \text { max }}}{3 \eta_{0}}$ decreases, the intensity of neck-in phenomenon as well as its sensitivity to draw ratio increases. It is also visible that for the given conditions and virtual materials used, there is always a critical draw ratio above which the dimensionless final film width (i.e. also the neck-in) becomes constant and draw ratio independent. Under such flow conditions, the applied extensional strains are high enough to reach steady state values in uniaxial and planar extensional viscosities. It is important to mention that such high draw down ratios $(\mathrm{DR}>20)$ are typically achieved in industrial high speed productions $[1,2]$. In order to follow industrial practice, our attention will focus on flow conditions at which the maximum draw ratio independent neck-in occurs. 


\section{The role of Deborah number}

In order to understand the role of Deborah number on the maximum attainable neck-in, its value was varied from 0.01 to 0.1 in the film casting model for all 15 virtual polymer melts keeping the $-\mathrm{N}_{2} / \mathrm{N}_{1}$ ratio the same, equal to 0.2 . For each simulation case, the draw ratio was adjusted high enough (typically equal to 40) in order to reach maximum and draw ratio independent neck-in value, NI. The maximum neck-in value was consequently normalized by the take-up length (stretching distance) $\mathrm{X}$ as follows

$$
\mathrm{NI}^{*}=\frac{\mathrm{NI}}{\mathrm{X}}
$$

Calculated maximum neck-in value $\mathrm{NI}^{*}$ as a function of the square root of planar to uniaxial

extensional viscosity ratio, $\operatorname{sqrt}\left(\eta_{\mathrm{E}, \mathrm{P}} / \eta_{\mathrm{E}, \mathrm{U}}\right)$, is provided in Figure $9 \mathrm{a}-9 \mathrm{c}$ for different Deborah numbers and uniaxial extensional strain hardening values. It is clear that an increase in the Deborah number increases both, the neck-in as well as its sensitivity to $\operatorname{sqrt}\left(\eta_{\mathrm{E}, \mathrm{P}} / \eta_{\mathrm{E}, \mathrm{U}}\right)$.

\section{Simple approximate and analytical solution for $\mathrm{NI}^{*}$}

Closer analysis of numerical solutions depicted in Figures $9 \mathrm{a}-9 \mathrm{c}$ reveals that $\mathrm{NI}^{*}$ varies with $\operatorname{sqrt}\left(\eta_{\mathrm{E}, \mathrm{P}} / \eta_{\mathrm{E}, \mathrm{U}}\right)$ almost linearly for all considered uniaxial extensional strain hardening levels. In order to quantify all calculated data, let us consider the following linear relationship between these two variables, i.e.:

$$
\mathrm{NI}^{*}=\mathrm{k}\left(\sqrt{\frac{\eta_{\mathrm{E}, \mathrm{P}}}{\eta_{\mathrm{E}, \mathrm{U}}}}-1\right)+\mathrm{Q}
$$


where $k$ (the slope of the line) and $Q$ (the $\mathrm{NI}^{*}$ intercept) are constants for given $D e$ and $\frac{\eta_{\mathrm{E}, \mathrm{U}, \text { max }}}{3 \eta_{0}}$. In order to capture the effect of $D e$ and $\frac{\eta_{\mathrm{E}, \mathrm{U}, \text { max }}}{3 \eta_{0}}$ on both constants, let us assume the following relationships for $k$ and $Q$ parameters (motivated by the well-known Avrami equation):

$$
\begin{aligned}
& \mathrm{k}^{*}=\mathrm{ka}_{\mathrm{S}}=\mathrm{A}_{1}\left[1-\exp \left(-\alpha_{1} D \mathrm{D}^{\varphi_{1}}\right)\right\rfloor \\
& \mathrm{Q}^{*}=\mathrm{Qa}_{\mathrm{S}}=\mathrm{A}_{2}\left[1-\exp \left(-\alpha_{2} D \mathrm{De}^{\varphi_{2}}\right)\right]
\end{aligned}
$$

where $A_{1}, A_{2}, \alpha_{1}, \alpha_{2}, \varphi_{1}, \varphi_{2}$ represent constants whereas $k^{*}$ and $Q^{*}$ are the reduced slope and reduced $N I^{*}$ intercept, respectively, and $a_{S}$ is the shift factor defined as

$$
a_{S}=\sqrt[10]{\frac{\eta_{E, U, \text { max }}}{3 \eta_{0}}}
$$

Eq. 75 was used to fit all numerical data provided in Figure $9 \mathrm{a}-9 \mathrm{c}$ in order to identify $k$ and $Q$ parameters for given Deborah numbers and $\frac{\eta_{\mathrm{E}, \mathrm{U}, \max }}{3 \eta_{0}}$ ratios. Both parameters were reduced by $a_{S}$ factor, plotted as the function of the Deborah number and finally fitted by Eqs. 76-77 to identify all model parameters, which are summarized in Table 4. Note that the fitting error was evaluated for both equations via the Root Mean Squared Error (RMSE) defined as

$$
\text { RMSE }=\sqrt{\frac{1}{n_{s}} \sum_{j=1}^{n_{s}}\left[y_{j}-\hat{y}_{j}\right]^{2}}
$$


where $n_{s}$ is the number of points whereas $\mathrm{y}_{\mathrm{j}}$ and $\hat{\mathrm{y}}_{\mathrm{j}}$ represent given and predicted points, respectively. Comparison between Deborah number dependent $k^{*}$ and $Q^{*}$ and model fits is provided in Figures 9d-9e. As it is shown, the suggested Eqs. 76-77 have the capability to describe $k^{*}$ and $Q^{*}$ parameters reasonably well.

If Eqs. 75-78 are combined together, the following expression for the normalized maximum neck-in is obtained

$$
\mathrm{NI}^{*}=\frac{1}{\sqrt[10]{\frac{\eta_{\mathrm{E}, \mathrm{U}, \text { max }}}{3 \eta_{0}}}}\left\{\mathrm{~A}_{1}\left[1-\exp \left(-\alpha_{1} D \mathrm{e}^{\varphi_{1}}\right)\right]\left(\sqrt{\frac{\eta_{\mathrm{E}, \mathrm{P}}}{\eta_{\mathrm{E}, \mathrm{U}}}}-1\right)+\mathrm{A}_{2}\left[1-\exp \left(-\alpha_{2} \mathrm{De}^{\varphi_{2}}\right)\right]\right\}
$$

This equation represents the final form of the simple analytical expression for the normalized and draw ratio independent neck-in value, which approximates the true numerical film casting model solution for the chosen range of Deborah numbers, $\frac{\eta_{E, U, m a x}}{3 \eta_{0}}$ and $\frac{\eta_{E, P}}{\eta_{E, U}}$ ratios. Comparison between the true numerical film casting model predictions and approximate solution (given by Eq. 80) for $\mathrm{NI}^{*}$ as a function of $\operatorname{sqrt}\left(\eta_{\mathrm{E}, \mathrm{P}} / \eta_{\mathrm{E}, \mathrm{U}}\right)$, De and $\frac{\eta_{\mathrm{E}, \mathrm{U}, \max }}{3 \eta_{0}}$ is provided in Figure 10. Based on this figure, it can be stated that the simple approximate solution model (Eq. 80) is capable of representing $\mathrm{NI}^{*}$ predictions of the utilized 1D viscoelastic membrane model predictions very well. 
If the Deborah number in Eq. 80 becomes high enough, the expression for $N I^{*}$ is simplified to

$$
\lim _{\mathrm{De} \rightarrow \infty} \mathrm{NI}^{*}=\frac{1}{\sqrt[10]{\frac{\eta_{\mathrm{E}, \mathrm{U}, \text { max }}}{3 \eta_{0}}}}\left[\mathrm{~A}_{1}\left(\sqrt{\frac{\eta_{\mathrm{E}, \mathrm{P}}}{\eta_{\mathrm{E}, \mathrm{U}}}}-1\right)+\mathrm{A}_{2}\right]
$$

As indicated from Table $4, A_{1}$ and $A_{2}$ constants are very similar. This suggests that both constants could be considered to be the same. This can be justified by the very small increase in RMSE (from 0.00726 to 0.01506) when this assumption is applied to identify corresponding $\alpha_{2}$ and $\varphi_{2}$ parameters via Eq. 77. Thus, considering that $\mathrm{A}_{2}=\mathrm{A}_{1}=0.553$, Eq. 81 simplifies to

$$
\lim _{\mathrm{De} \rightarrow \infty} \mathrm{NI}^{*}=\frac{0.553}{\sqrt[10]{\frac{\eta_{\mathrm{E}, \mathrm{U}, \max }}{3 \eta_{0}}}} \sqrt{\frac{\eta_{\mathrm{E}, \mathrm{P}}}{\eta_{\mathrm{E}, \mathrm{U}}}}
$$

Based on Eq. 82, it can be concluded that the maximum attainable $N I^{*}$, which is given by the approximate solution at very high Deborah numbers, is a linear function of $\sqrt{\frac{\eta_{E, P}}{\eta_{E, U}}}$ with a slope of $\frac{0.553}{\sqrt[10]{\frac{\eta_{\mathrm{E}, \mathrm{U}, \mathrm{max}}}{3 \eta_{0}}}}$

\section{Simple approximate solution for NI $^{*}$ vs. experimental data}

In this part, the validity of the simple approximate solution for $N I^{*}$, which is given by Eq. 80 and parameters provided in Table 4, is tested for the Dow LDPE 170A sample (see Table 1) as well as for three additional PE samples taken from [26], whose basic characteristics are 
provided in Table 5. Normalized maximum neck-in, $N I^{*}$, together with the corresponding extrusion film casting processing parameters for each polymer sample are taken from [26,45] and they are summarized in Table 6.

In the first step, deformation rate dependent uniaxial extensional viscosity data were successfully fitted for each polymer melt at given temperature by the single mode modified Leonov model, as it can be seen in Figure 11. Model parameters for PE-A, PE-B and PE-C samples are provided in Table 7 for $130{ }^{\circ} \mathrm{C}$. Note, that the Leonov model parameters for the Dow LDPE 170A sample have already been identified in the 'Film Casting Model Validation' section (see Figure 5a) and they are provided in Table 2.

In the second step, Leonov model relaxation times, which are provided in Table 2 and Table 7 for given polymer samples, were shifted to the particular processing temperature by using the Arrhenius shift factor and the flow activation energy, i.e. from $150{ }^{\circ} \mathrm{C}$ to $190{ }^{\circ} \mathrm{C}$ for LDPE $170 \mathrm{~A}$ and from $130{ }^{\circ} \mathrm{C}$ to $320{ }^{\circ} \mathrm{C}$ for PE-A, PE-B and PE-C samples. This allows calculation of Deborah number according to Eq. 42 via shifted Leonov model relaxation time and process parameters $u_{0}$ (die exit velocity) and $X$ (air gap) provided in Table 6 . In order to evaluate the average value of planar to uniaxial extensional viscosity ratio, $\frac{\eta_{E, P}}{\eta_{E, U}}$, by using modified Leonov model, one needs to determine the mean value of deformation rate in the machine direction, $d u / d x$. This variable was estimated here as the ratio of velocity difference between the die and roll $\left(\mathrm{u}-\mathrm{u}_{0}\right)$ and stretching distance $X$, which can be justifiable for linear velocity profiles typically occurring for LDPE polymer melts [45,46,48]. Uniaxial extensional strain hardening, $\frac{\eta_{\mathrm{E}, \mathrm{U}, \mathrm{max}}}{3 \eta_{0}}$, is simply given by the modified Leonov model for given material and processing temperature. All estimated parameters, which are needed to calculate the maximum normalized neck-in value, $N I^{*}$, via the approximate model (Eq. 80 ), are summarized in Table 8 for the given materials and processing conditions. 
Comparison between the measured $N I^{*}$ and approximate model predictions, utilizing parameters summarized in Table 8, is provided in Figure 12. As it can be seen, the simple approximate model can predict neck-in value $N I^{*}$ for the considered LDPE polymer melts and Deborah numbers very well. Eq. 80 can thus be considered as a useful tool for optimization of process conditions and polymer melt rheology to minimize neck-in phenomena during thin flat film production under industrial processing conditions.

It is important to mention that utilization of Eqs. 80 requires experimental determination of the planar-to-uniaxial extensional viscosity ratio, which is one of the most challenging rheological tasks because generation and control of the extensional flow is difficult. Just recently, it has been shown that planar and uniaxial extensional viscosity can be measured in a wide temperature and deformation rate range by using a standard twin bore capillary rheometer, with novel rectangular and circular orifice (zero-length) dies and the Cogswell model [59]. 


\section{CONCLUSIONS}

In this work, viscoelastic, isothermal extrusion film casting modeling utilizing a 1D membrane model and a single-mode modified Leonov model was performed in order to understand the role of uniaxial extensional strain hardening, planar-to-uniaxial extensional viscosity ratio and Deborah number on the neck-in phenomenon. For model validation purposes, basic dimensionless variables measured in $[45,46,48]$ for LDPE polymer melt such as film half-width, half-thickness and center-line velocity as the function of stretching distance, DR and Deborah numbers were used. It was found that the film casting modeling by using multi-mode XPP model and modified Leonov model is comparable for the given LDPE polymer and processing conditions even though, surprisingly, a single-mode version of the Leonov model was used. The consequent parametric study revealed that firstly, if planar to uniaxial extensional viscosity ratio, $\frac{\eta_{\mathrm{E}, \mathrm{P}}}{\eta_{\mathrm{E}, \mathrm{U}}}$, decreases or uniaxial extensional strain hardening increases, $\frac{\eta_{\mathrm{E}, \mathrm{U}, \mathrm{max}}}{3 \eta_{0}}$, intensity of neck-in phenomenon as well as its sensitivity to draw ratio decreases and secondly, an increase in the Deborah number increases both, the neck-in as well as its sensitivity to $\frac{\eta_{E, P}}{\eta_{E, U}}$. Obtained numerical solutions were successfully approximated by a simple dimensionless analytical equation relating maximum attainable neck-in value with $\frac{\eta_{E, U, m a x}}{3 \eta_{0}}, \frac{\eta_{E, P}}{\eta_{E, U}}$ and Deborah number. The validity of the suggested equation was tested by using experimental data taken from the open literature $[26,45,46]$ for four different polyethylene melts, for which $\quad 0.011 \leq \mathrm{De} \leq 0.061, \quad 0.833 \leq \frac{\eta_{\mathrm{E}, \mathrm{P}}}{\eta_{\mathrm{E}, \mathrm{U}}} \leq 1.293 \quad$ and $2.047 \leq \frac{\eta_{E, U, \max }}{3 \eta_{0}} \leq 9.299$. It was found that the proposed equation can describe for the given 
polymer melts and processing conditions the experimental data very well. Thus, it is believed that this simple model can be used for material, die design and process conditions optimization in order to minimize unwanted neck-in phenomenon in cast film production.

\section{Acknowledgments}

The authors wish to acknowledge the financial support from the Grant Agency of the Czech Republic (Grant registration No. 16-05886S). 


\section{REFFERENCES}

[1] T. Kanai, G.A. Campbell, Film Processing, Hanser Publishers, 1999.

[2] T. Kanai, G.A. Campbell, Film Processing Advances, Second Edi, Carl Hanser Verlag GmbH \& Co. KG, München, 2014.

[3] A. Co, Chapter 10 Draw Resonance in Film Casting, in: S.G. Hatzikiriakos, K.B. Migler (Eds.), Polym. Process. Instab. Control Underst., CRC Press, 2005: p. 488.

[4] H.W. Jung, J.C. Hyun, Chapter 11 Fiber Spinning and Film Blowing Instabilities, in: S.G. Hatzikiriakos, K.B. Migler (Eds.), Polym. Process. Instab. Control Underst., CRC Press, 2005: p. 488.

[5] D. Gelder, The stability of fiber drawing processes, Ind. Eng. Chem. Fundam. 10 (1971), pp. 534-535.

[6] R.J. Fisher, M.M. Denn, Finite-amplitude stability and draw resonance in isothermal melt spinning, Chem. Eng. Sci. 30 (1975), pp. 1129-1134.

[7] R.J. Fisher, M.M. Denn, A theory of isothermal melt spinning and draw resonance, AIChE J. 22 (1976), pp. 236-246.

[8] R.E. Christensen, Extrusion coating of polypropylene, SPE J. 18 (1962), pp. 751.

[9] J.C. Miller, Swelling behavior in extrusion, SPE Trans. 3 (1963), pp. 134-137.

[10] Y.L. Yeow, On the stability of extending films: a model for the film casting process, $J$. Fluid Mech. 66 (1974), pp. 613-622.

[11] G.R. Aird, Y.L. Yeow, Stability of film casting of power-law liquids, Ind. Eng. Chem. Fundam. 22 (1983), pp. 7-10.

[12] N.R. Anturkar, A. Co, Draw resonance in film casting of viscoelastic fluids: A linear stability analysis, J. Nonnewton. Fluid Mech. 28 (1988), pp. 287-307.

[13] V.R. Iyengar, A. Co, Film casting of a modified Giesekus fluid: a steady-state analysis, J. Nonnewton. Fluid Mech. 48 (1993), pp. 1-20.

[14] V.R. Iyengar, A. Co, Film casting of a modified Giesekus fluid: Stability analysis, Chem. Eng. Sci. 51 (1996), pp. 1417-1430.

[15] J.-P. Sergent, Etude de deux proce'de's de fabrication de films. Le soufflage de gaine. L'extrusion de film a plat., Universite Louis Pasteur, Strasbourg, France, 1977.

[16] D. Cotto, P. Duffo, J.M. Haudin, Cast film extrusion of polypropylene films, Int. Polym. Process. 4 (1989), pp. 103-113.

[17] P. Duffo, B. Monasse, J.M. Haudin, Cast film extrusion of polypropylene. Thermomechanical and physical aspects, J. Polym. Eng. 10 (1991), pp. 151-229. 
[18] P. Barq, J.M. Haudin, J.F. Agassant, Isothermal and anisothermal models for cast film extrusion, Int. Polym. Process. 7 (1992), pp. 334-349.

[19] T. Dobroth, L. Erwin, Causes of edge beads in cast films, Polym. Eng. Sci. 26 (1986), pp. $462-467$.

[20] B. Debbaut, J.M. Marchal, M.J. Crochet, Viscoelastic effects in film casting, in: J. Casey, M.J. Crochet (Eds.), Theor. Exp. Numer. Contrib. to Mech. Fluids Solids, Birkhauser Verlag, Basel, Switzerland; (Boston, Berlin), 1995: pp. 679-698.

[21] N. Toft, M. Rigdahl, Extrusion coating with metallocene-catalysed polyethylenes, Int. Polym. Process. 17 (2002), pp. 244-253.

[22] S. Kouda, Prediction of processability at extrusion coating for low-density polyethylene, Polym. Eng. Sci. 48 (2008), pp. 1094-1102.

[23] N. Satoh, H. Tomiyama, T. Kajiwara, Viscoelastic simulation of film casting process for a polymer melt, Polym. Eng. Sci. 41 (2001), pp. 1564-1579.

[24] H. Ito, M. Doi, T. Isaki, M. Takeo, A Model of Neck-in Phenomenon in Film Casting Process, J. Soc. Rheol. Japan. 31 (2003), pp. 157-163.

[25] S. Shiromoto, Y. Masutani, M. Tsutsubuchi, Y. Togawa, T. Kajiwara, A neck-in model in extrusion lamination process, Polym. Eng. Sci. 50 (2010), pp. 22-31.

[26] S. Shiromoto, Y. Masutani, M. Tsutsubuchi, Y. Togawa, T. Kajiwara, The effect of viscoelasticity on the extrusion drawing in film-casting process, Rheol. Acta. 49 (2010), pp. 757-767.

[27] S. Shiromoto, The Mechanism of Neck-in Phenomenon in Film Casting Process, Int. Polym. Process. 29 (2014), pp. 197-206.

[28] S. D’Halewyu, J.F. Agassant, Y. Demay, Numerical simulation of the cast film process, Polym. Eng. Sci. 30 (1990), pp. 335-340.

[29] D. Silagy, Y. Demay, J.F. Agassant, Study of the stability of the film casting process, Polym. Eng. Sci. 36 (1996), pp. 2614-2625.

[30] O.S. Narayanaswamy, A One-Dimensional Model of Stretching Float Glass, J. Am. Ceram. Soc. 60 (1977), pp. 1-5.

[31] D. Silagy, Y. Demay, J.F. Agassant, Stationary and stability analysis of the film casting process, J. Nonnewton. Fluid Mech. 79 (1998), pp. 563-583.

[32] G. Lamberti, G. Titomanlio, V. Brucato, Measurement and modelling of the film casting process 1. Width distribution along draw direction, Chem. Eng. Sci. 56 (2001), pp. 5749-5761.

[33] G. Lamberti, G. Titomanlio, V. Brucato, Measurement and modelling of the film 
casting process 2. Temperature distribution along draw direction, Chem. Eng. Sci. 57 (2002), pp. 1993-1996.

[34] G. Lamberti, V. Brucato, G. Titomanlio, Orientation and crystallinity in film casting of polypropylene, J. Appl. Polym. Sci. 84 (2002), pp. 1981-1992.

[35] G. Lamberti, F. De Santis, V. Brucato, G. Titomanlio, Modeling the interactions between light and crystallizing polymer during fast cooling, Appl. Phys. A. 78 (2004), pp. 895-901.

[36] G. Titomanlio, G. Lamberti, Modeling flow induced crystallization in film casting of polypropylene, Rheol. Acta. 43 (2004), pp. 146-158.

[37] G. Lamberti, G. Titomanlio, Analysis of film casting process: The heat transfer phenomena, Chem. Eng. Process. Process Intensif. 44 (2005), pp. 1117-1122.

[38] G. Lamberti, G. Titomanlio, Analysis of Film Casting Process : Effect of Cooling during the Path in Air, Ind. Eng. Chem. Res. 45 (2006), pp. 719-723.

[39] G. Lamberti, Flow-induced crystallization during isotactic polypropylene film casting, Polym. Eng. Sci. 51 (2011), pp. 851-861.

[40] K. Sakaki, R. Katsumoto, T. Kajiwara, K. Funatsu, Three-dimensional flow simulation of a film-casting process, Polym. Eng. Sci. 36 (1996), pp. 1821-1831.

[41] H. Zheng, W. Yu, C. Zhou, H. Zhang, Three-Dimensional Simulation of the NonIsothermal Cast Film Process of Polymer Melts, J. Polym. Res. 13 (2006), pp. 433440.

[42] H. Ito, M. Doi, T. Isaki, M. Takeo, K. Yagi, 2D Flow Analysis of Film Casting Process, J. Soc. Rheol. Japan. 31 (2003), pp. 149-155.

[43] C.W. Seay, D.G. Baird, Sparse Long-chain Branching's Effect on the Film-casting Behavior of PE, Int. Polym. Process. 24 (2009), pp. 41-49.

[44] C.D. McGrady, C.W. Seay, D.G. Baird, Effect of sparse long-chain branching on the film-casting behavior for a series of well-defined HDPEs, Int. Polym. Process. 24 (2009), pp. 428-438.

[45] H. V. Pol, S.S. Thete, P. Doshi, A.K. Lele, Necking in extrusion film casting: The role of macromolecular architecture, J. Rheol. 57 (2013), pp. 559-583.

[46] H. Pol, S. Banik, L.B. Azad, S.S. Thete, P. Doshi, A. Lele, Nonisothermal analysis of extrusion film casting process using molecular constitutive equations, Rheol. Acta. $\mathbf{5 3}$ (2014), pp. 85-101.

[47] K. Chikhalikar, S. Banik, L.B. Azad, K. Jadhav, S. Mahajan, Z. Ahmad, S. Kulkarni, S. Gupta, P. Doshi, H. Pol, A. Lele, Extrusion film casting of long chain branched 
polypropylene, Polym. Eng. Sci. 55 (2015), pp. 1977-1987.

[48] S.S. Thete, P. Doshi, H. V. Pol, New insights into the use of multi-mode phenomenological constitutive equations to model extrusion film casting process, $J$. Plast. Film Sheeting. 33 (2017), pp. 35-71.

[49] A.I. Leonov, Nonequilibrium Thermodynamics and Rheology of Viscoelastic Polymer Media, Rheol. Acta. 15 (1976), pp. 85-98.

[50] A.I. Leonov, E.H. Lipkina, E.D. Paskhin, A.N. Prokunin, Theoretical and experimental investigation of shearing in elastic polymer liquids, Rheol. Acta. 15 (1976), pp. 411426.

[51] A.I. Leonov, A.N. Prokunin, An improved simple version of a nonlinear theory of elasto-viscous polymer media, Rheol. Acta. 19 (1980), pp. 393-403.

[52] A.I. Leonov, A.N. Prokunin, On nonlinear effects in the extensional flow of polymeric liquids, Rheol. Acta. 22 (1983), pp. 137-150.

[53] M. Simhambhatla, A.I. Leonov, On the rheological modeling of viscoelastic polymer liquids with stable constitutive equations, Rheol. Acta. 34 (1995), pp. 259-273.

[54] A.I. Leonov, Constitutive equations for viscoelastic liquids: Formulation, analysis and comparison with data, Rheol. Ser. 8 (1999), pp. 519-575.

[55] M. Zatloukal, Differential viscoelastic constitutive equations for polymer melts in steady shear and elongational flows, J. Nonnewton. Fluid Mech. 113 (2003), pp. 209227.

[56] D. Acierno, L. Di Maio, C.C. Ammirati, Film casting of polyethylene terephthalate: Experiments and model comparisons, Polym. Eng. Sci. 40 (2000), pp. 108-117.

[57] M. Beaulne, E. Mitsoulis, Numerical Simulation of the Film Casting Process, Int. Polym. Process. 14 (1999), pp. 261-275.

[58] E.A. Jensen, J. deC. Christiansen, Measurements of first and second normal stress differences in a polymer melt, J. Nonnewton. Fluid Mech. 148 (2008), pp. 41-46.

[59] M. Zatloukal, Measurements and modeling of temperature-strain rate dependent uniaxial and planar extensional viscosities for branched LDPE polymer melt, Polymer. 104 (2016), pp. 258-267. 


\section{LIST OF SYMBOLS}

\begin{tabular}{|c|c|}
\hline$\underline{\tau}$ & Extra stress tensor \\
\hline$\underline{\sigma}$ & Total stress tensor \\
\hline $\mathrm{W}$ & Elastic potential \\
\hline $\mathrm{G}$ & $\begin{array}{l}\text { Linear Hookean elastic modulus (Relaxation } \\
\text { modulus) }\end{array}$ \\
\hline$\underline{\underline{\mathrm{c}}}, \underline{\mathrm{c}}_{\mathrm{ii}}$ & Recoverable Finger tensor \\
\hline 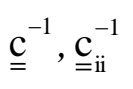 & Inverse recoverable Finger tensor \\
\hline $\mathrm{I}_{1, \mathrm{c}}$ & First invariant of recoverable Finger tensor \\
\hline $\mathrm{I}_{2, \mathrm{c}}$ & Second invariant of recoverable Finger tensor \\
\hline$\beta$ & Non-linear Leonov model parameter \\
\hline $\mathrm{n}$ & Non-linear Leonov model parameter \\
\hline$\stackrel{e}{=}$ & Irreversible rate of strain tensor \\
\hline $\mathrm{b}$ & Dissipation term \\
\hline$\underline{\underline{\delta}}$ & Unit tensor (Kronecker delta) \\
\hline$\underline{\underline{D}}$ & Deformation rate tensor \\
\hline$\lambda$ & Relaxation time \\
\hline$\xi$ & Non-linear Leonov model parameter \\
\hline$v$ & Non-linear Leonov model parameter \\
\hline $\begin{array}{l}0 \\
\stackrel{c}{=}\end{array}$ & $\begin{array}{l}\text { Jaumann (corotational) time derivative of the } \\
\text { recoverable Finger strain tensor }\end{array}$ \\
\hline $\mathrm{N}_{1}$ & First normal stress difference \\
\hline $\mathrm{N}_{2}$ & Second normal stress difference \\
\hline
\end{tabular}


Total normal stress in the axial direction (machine direction)

Total normal stress in y-direction

$\mathrm{Pa}$

Total normal stress in z-direction

$\mathrm{Pa}$

Normal stress in the axial direction (machine direction)

Normal stress in y-direction (transverse direction)

$\mathrm{Pa}$

Normal stress in z-direction (thickness direction)

$\mathrm{Pa}$

Isotropic pressure

$\mathrm{Pa}$

Component of the recoverable Finger tensor in $\mathrm{x}$-direction

Component of the recoverable Finger tensor in y-direction

Component of the recoverable Finger tensor in $\mathrm{z}$-direction

Half-thickness of the film at any $\mathrm{x}$ location

$\mathrm{mm}$

Half-width of the film at any $\mathrm{x}$ location

$\mathrm{mm}$

Axial velocity of the film at any $x$ location

$\mathrm{mm} \cdot \mathrm{s}^{-1}$

Chill roll speed

$\mathrm{mm} \cdot \mathrm{s}^{-1}$

Take-up force (stretching force)

$\mathrm{N}$

Dimensionless force

1

Position in $\mathrm{x}$-direction

$\mathrm{m}$

Velocity of the film in $y$-direction at any $x$ location

$\mathrm{mm} \cdot \mathrm{s}^{-1}$

Velocity of the film in z-direction at any $\mathrm{x}$

$\mathrm{mm} \cdot \mathrm{s}^{-1}$ 
location

f

g

$\mathrm{e}_{0}$

$\mathrm{L}_{0}$

$\mathrm{u}_{0}$

X

DR

A

De

$\overline{\mathrm{x}}$

$\overline{\mathrm{e}}$

$\overline{\mathrm{L}}$

$\overline{\mathrm{u}}$

$\bar{\tau}_{\mathrm{xx}}$

$\bar{\tau}_{\mathrm{yy}}$

$\bar{\tau}_{\mathrm{zz}}$

$\overline{\mathrm{f}}$

$\overline{\mathrm{g}}$

Rate of deformation in y-direction $\quad \mathrm{s}^{-1}$

Rate of deformation in z-direction $\quad \mathrm{s}^{-1}$

Die half-gap (half-thickness of the film at the die exit)

$\mathrm{mm}$

Half-width of the die (half-width of the film at the die exit)

$\mathrm{mm}$

Axial velocity at the die exit (velocity in the machine direction)

$\mathrm{mm} \cdot \mathrm{s}^{-1}$

Take-up length (stretching distance)

$\mathrm{mm}$

Draw ratio 1

Aspect ratio 1

Deborah number 1

Dimensionless position in $\mathrm{x}$-direction $\quad 1$

Dimensionless half-thickness of the film at any $\mathrm{x}$ location

Dimensionless half-width of the film at any $\mathrm{x}$ location

Dimensionless axial velocity of the film at any $\mathrm{x}$ location

1

Dimensionless normal stress in y-direction $\quad 1$

Dimensionless normal stress in z-direction $\quad 1$

Dimensionless rate of deformation in

y-direction

Dimensionless rate of deformation in z-direction 


$$
\mathrm{Z}_{\mathrm{x}}, \mathrm{Z}_{\mathrm{y}}, \mathrm{Z}_{\mathrm{z}}, \mathrm{X}_{\mathrm{p}}
$$

$\underline{\mathrm{u}}$

$\underline{\mathrm{n}}$

Q

$\mathrm{T}$

$\mathrm{T}_{\text {die }}$

$\mathrm{T}_{\mathrm{r}}$

$\mathrm{E}_{\mathrm{a}}$

$\mathrm{R}$

i

$\mathrm{j}$

$a_{s}$

$\mathrm{x}, \mathrm{y}, \mathrm{z}$

$\mathrm{t}$

$\eta_{\mathrm{E}, \mathrm{U}}$

$\eta_{E, P}$

$\eta_{0}$

$\eta_{\mathrm{E}, \mathrm{U}, \max }$

$\eta_{\mathrm{E}, \mathrm{P}, \max }$

NI

$\mathrm{NI}^{*}$
Substitution variables

The tangential velocity at film-air interface

The normal vector to the free surface

Volumetric flow rate

Melt temperature

Melt temperature at the die

Reference temperature in the Arrhenius Law

Flow activation energy

Gas constant

Relaxation mode identification number

Index $\mathrm{j}$

Shift parameter for normalized necking prediction

Spatial coordinates

Time coordinate

Steady uniaxial extensional viscosity

Steady planar extensional viscosity

Newtonian viscosity

Maximal steady uniaxial extensional viscosity

Maximal steady planar extensional viscosity

Maximum neck-in

Normalized maximum neck-in value
S

$\mathrm{Pa} \cdot \mathrm{s}$

$\mathrm{mm}$

1

$\mathrm{mm} \cdot \mathrm{s}^{-1}$

1

$\mathrm{m}^{3} \cdot \mathrm{s}^{-1}$

${ }^{\circ} \mathrm{C}$

${ }^{\circ} \mathrm{C}$

${ }^{\circ} \mathrm{C}$

$\mathrm{J} \cdot \mathrm{mol}^{-1}$

$\mathrm{J} \cdot \mathrm{K}^{-1} \cdot \mathrm{mol}^{-1}$

1

1

1

1

$\mathrm{Pa} \cdot \mathrm{s}$

$\mathrm{Pa} \cdot \mathrm{s}$

$\mathrm{Pa} \cdot \mathrm{s}$

$\mathrm{Pa} \cdot \mathrm{s}$

1 
$\mathrm{A}_{1}, \mathrm{~A}_{2}$

$\varphi_{1}, \varphi_{2}$

$\mathrm{n}_{\mathrm{s}}$

Number of samples (points)

1

$\mathrm{y}_{\mathrm{i}}$

Observed value

Predicted value

$\mathrm{M}_{\mathrm{w}}$

Mass average molar mass

$\mathrm{g} \cdot \mathrm{mol}^{-1}$

$\mathrm{M}_{\mathrm{n}}$

Number average molar mass

$\mathrm{g} \cdot \mathrm{mol}^{-1}$

$\mathrm{M}_{\mathrm{z}}$

$\mathrm{Z}$ average molar mass

$\mathrm{g} \cdot \mathrm{mol}^{-1}$

MFR

Mass flow rate

$\mathrm{kg} \cdot \mathrm{h}^{-1}$

$\mathrm{R}_{\mathrm{h}}$

The hydrodynamic radius of a macromolecule

$\mathrm{nm}$

PDI

Polydispersity index

1

MFI

Mass flow index

$\mathrm{g} / 10 \mathrm{~min}$

$\rho$

Polymer density

$\mathrm{g} \cdot \mathrm{cm}^{-3}$ 
Table 1. Molecular characteristics for Dow LDPE 170A with density $0.924 \mathrm{~g} / \mathrm{cm}^{3}$ and MFI $0.7 \mathrm{~g} / 10 \mathrm{~min}\left(190^{\circ} \mathrm{C}, 2.16 \mathrm{~kg}\right)$ [48].

\begin{tabular}{|c|c|c|c|c|c|c|c|}
\hline $\begin{array}{c}\mathbf{M n} \\
(\mathrm{g} / \mathrm{mol})\end{array}$ & $\begin{array}{c}\mathbf{M w} \\
(\mathrm{g} / \mathrm{mol})\end{array}$ & $\begin{array}{c}\mathbf{M z} \\
(\mathrm{g} / \mathrm{mol})\end{array}$ & $\begin{array}{c}\text { PDI } \\
(1)\end{array}$ & $\begin{array}{c}\text { Newtonian } \\
\text { viscosity } \\
\mathbf{a t ~ 1 5 0}^{\circ} \mathbf{C} \\
(\mathrm{Pa} \cdot \mathrm{s})\end{array}$ & $\begin{array}{c}\mathbf{R h} \\
(\mathrm{nm})\end{array}$ & $\begin{array}{c}\text { LCB (per } \\
\mathbf{1 0 0 0 0} \mathbf{C} \\
\mathbf{a t o m s}^{\#}\end{array}$ & $\begin{array}{c}\text { Branched } \geq 6 \\
\mathbf{C} \text { atoms (per } \\
\mathbf{1 0 0 0 0} \mathbf{C} \\
\text { atoms) }\end{array}$ \\
\hline 30600 & 185900 & 528400 & 6.07 & 134992.70 & 10.88 & 11 & 80 \\
\hline
\end{tabular}

\# Data acquired from HT-GPC (High-temperature Gel Permeation Chromatography)

\#\# Data acquired from HT-NMR (High-temperature Nuclear Magnetic Resonance)

PDI - Polydispersity Index

LCB - Long Chain Branching

Table 2. Modified Leonov model parameters for $\mathrm{T}=150{ }^{\circ} \mathrm{C}$; LDPE $170 \mathrm{~A}$.

\begin{tabular}{|c|c|c|c|c|}
\hline$\lambda(\mathrm{s})$ & $\mathbf{G}(\mathrm{Pa})$ & $\boldsymbol{\xi}(1)$ & $\mathbf{v}(1)$ & $\boldsymbol{\beta}(1)$ \\
\hline 1.57 & 85982.61 & 1.816 & 0.174 & 0.4 \\
\hline
\end{tabular}

Table 3. Modified Leonov model parameters for the utilized virtual polymer melts at $150{ }^{\circ} \mathrm{C}$.

\begin{tabular}{|c|c|c|c|c|c|c|c|}
\hline Virtual Material Name & $\lambda(\mathrm{s})$ & $\mathbf{G}(\mathrm{Pa})$ & $\xi(1)$ & $\boldsymbol{v}(1)$ & $\boldsymbol{\beta}(1)$ & $\frac{\eta_{\mathrm{E}, \mathrm{U}, \max }}{3 \eta_{0}}$ & $\frac{\eta_{\mathrm{E}, \mathrm{P}, \max }}{4 \eta_{0}}$ \\
\hline Melt1_High & 1.57 & 85982.61 & 4.414 & 0.276 & 0.1 & 7.1 & 6.2 \\
\hline Melt2_High & 1.57 & 85982.61 & 4.042 & 0.208 & 0.3 & 7.1 & 6.6 \\
\hline Melt3_High & 1.57 & 85982.61 & 3.816 & 0.174 & 0.4 & 7.1 & 6.8 \\
\hline Melt4_High & 1.57 & 85982.61 & 3.54 & 0.14 & 0.5 & 7.1 & 7.1 \\
\hline Melt5_High & 1.57 & 85982.61 & 2.806 & 0.072 & 0.7 & 7.1 & 7.9 \\
\hline Melt1_Middle & 1.57 & 85982.61 & 2.014 & 0.276 & 0.1 & 3.4 & 2.9 \\
\hline Melt2_Middle & 1.57 & 85982.61 & 1.882 & 0.208 & 0.3 & 3.4 & 3.1 \\
\hline Melt3_Middle & 1.57 & 85982.61 & 1.816 & 0.174 & 0.4 & 3.4 & 3.2 \\
\hline Melt4_Middle & 1.57 & 85982.61 & 1.75 & 0.14 & 0.5 & 3.4 & 3.4 \\
\hline Melt5_Middle & 1.57 & 85982.61 & 1.53 & 0.072 & 0.7 & 3.4 & 4.2 \\
\hline Melt1_Low & 1.57 & 85982.61 & 0.338 & 0.276 & 0.1 & 1.3 & 1.10 \\
\hline Melt2_Low & 1.57 & 85982.61 & 0.38 & 0.208 & 0.3 & 1.3 & 1.17 \\
\hline Melt3_Low & 1.57 & 85982.61 & 0.4 & 0.174 & 0.4 & 1.3 & 1.22 \\
\hline Melt4_Low & 1.57 & 85982.61 & 0.418 & 0.14 & 0.5 & 1.3 & 1.29 \\
\hline Melt5_Low & 1.57 & 85982.61 & 0.426 & 0.072 & 0.7 & 1.3 & 1.53 \\
\hline
\end{tabular}


Table 4. Parameters for Eqs. 76-77 defining $k$ and $Q$ values.

\begin{tabular}{|c|c|c|c|c|c|}
\hline $\mathbf{f}(\mathbf{D e})$ & $\mathbf{j}$ & $\mathbf{A}_{\mathbf{j}}$ & $\boldsymbol{\alpha}_{\mathbf{j}}$ & $\boldsymbol{\varphi}_{\mathbf{j}}$ & $\mathbf{R M S D}$ \\
\hline Reduced slope & 1 & 0.553 & 2287.854 & 2.323 & 0.0255 \\
\hline Reduced NI* intercept & 2 & 0.512 & 66.712 & 1.087 & 0.00726 \\
\hline
\end{tabular}

Table 5. Basic characteristics for PE-A, PE-B and PE-C samples [26].

\begin{tabular}{|c|c|c|c|c|c|c|}
\hline $\begin{array}{c}\text { Polymer } \\
\text { sample }\end{array}$ & $\begin{array}{c}\text { MFI } \\
(\mathrm{g} / 10 \mathrm{~min})\end{array}$ & $\begin{array}{c}\text { Melt } \\
\mathbf{T e n s i o n} \\
(\mathrm{cN})\end{array}$ & $\begin{array}{c}\mathbf{M}_{\mathbf{w}} \\
(\mathrm{kg} / \mathrm{mol})\end{array}$ & $\begin{array}{c}\mathbf{M}_{\mathbf{w}} / \mathbf{M}_{\mathbf{n}} \\
(1)\end{array}$ & $\begin{array}{c}\text { Newtonian } \\
\text { viscosity at 130 } \\
(\mathrm{Pa} \cdot \mathrm{s})\end{array}$ & $\begin{array}{c}\text { Polymerization } \\
\text { Process }\end{array}$ \\
\hline PE-A & 6.7 & 2.1 & 163 & 9.1 & 16220 & Autoclave \\
\hline PE-B & 4.1 & 3.3 & 102 & 6.6 & 37720 & Tubular \\
\hline PE-C & 4.3 & 1.9 & 85 & 6.0 & 36033 & Tubular \\
\hline
\end{tabular}

Flow activation energy, $E_{a}$, for all three samples is $49.887 \mathrm{~kJ} / \mathrm{mol}$. Note, that $E_{a}$ was calculated here as $\mathrm{E}_{\mathrm{a}}=\alpha \cdot \mathrm{R}$, where $\alpha$ is Arrhenius law parameter equal to $6000 \mathrm{~K}$ provided in [26] and $R$ is the universal gas constant equal to $8.3144598 \mathrm{~J} / \mathrm{K} / \mathrm{mol}$.

Table 6. Extrusion film casting processing parameters for all considered polymer samples taken from the open literature.

\begin{tabular}{|c|c|c|c|c|c|c|c|c|}
\hline $\begin{array}{c}\text { Polymer } \\
\text { sample }\end{array}$ & $\begin{array}{c}\text { Die } \\
\text { Width } \\
(\mathrm{mm})\end{array}$ & $\begin{array}{c}\text { Die Gap } \\
(\mathrm{mm})\end{array}$ & $\begin{array}{c}\text { Air } \\
\text { Gap } \\
(\mathrm{mm})\end{array}$ & $\begin{array}{c}\text { Temperature } \\
\left({ }^{\circ} \mathrm{C}\right)\end{array}$ & $\begin{array}{c}\text { Die Exit } \\
\text { Velocity } \\
(\mathrm{mm} / \mathrm{s})\end{array}$ & $\begin{array}{c}\text { Draw } \\
\text { Ratio } \\
(1)\end{array}$ & $\begin{array}{c}\text { NI* } \\
(1)\end{array}$ & $\begin{array}{c}\text { Refer- } \\
\text { ence }\end{array}$ \\
\hline $\begin{array}{c}\text { LDPE } \\
\text { 170A }\end{array}$ & 100 & 0.46 & 228 & 190 & 4.3 & 17.1 & 0.1537 & {$[45]$} \\
\hline PE-A & 600 & 0.80 & 160 & 320 & $46.6^{\#}$ & $42.91^{\# \#}$ & 0.2466 & {$[26]$} \\
\hline PE-B & 600 & 0.80 & 190 & 320 & $46.6^{\#}$ & $42.91^{\# \#}$ & 0.3275 & {$[26]$} \\
\hline PE-C & 600 & 0.80 & 220 & 320 & $46.6^{\#}$ & $42.91^{\# \#}$ & 0.5159 & {$[26]$} \\
\hline
\end{tabular}

${ }^{\#}$ Die exit velocity was determined based on the die width $\left(L_{0}\right)$, die gap $\left(e_{0}\right)$, melt density $(\rho)$ and mass flow rate $(M F R)$ as $\mathrm{u}_{0}=\mathrm{MFR} /\left(\rho \mathrm{L}_{0} \mathrm{e}_{0}\right)$, where $\mathrm{MFR}=60 \mathrm{~kg} / \mathrm{h}$ and melt density $\rho=745 \mathrm{~kg} / \mathrm{m}^{3}[26]$.

\#\# Draw ratio was determined from die exit velocity and take-up velocity as $\mathrm{DR}=\mathrm{u} / \mathrm{u}_{0}$. Takeup velocity is provided in [26] as $\mathrm{u}=120 \mathrm{~m} / \mathrm{min}$. 
Table 7. Modified Leonov model parameters for PE-A, PE-B and PE-C polymer samples at $130{ }^{\circ} \mathrm{C}$.

\begin{tabular}{|c|c|c|c|c|c|}
\hline Polymer sample & $\boldsymbol{\lambda}(\mathrm{s})$ & $\mathbf{G}(\mathrm{Pa})$ & $\boldsymbol{\xi}(1)$ & $\boldsymbol{v}(1)$ & $\boldsymbol{\beta}(1)$ \\
\hline PE-A & 9.5 & 1707.37 & 0.41 & 0.0015 & 0.4 \\
\hline PE-B & 15 & 2514.67 & 0.29 & 0.0034 & 0.4 \\
\hline PE-C & 30 & 1201.10 & 0.09 & 0.0013 & 0.5 \\
\hline
\end{tabular}

Table 8. Analytical model parameters for all considered polymer materials for the given processing parameters.

\begin{tabular}{|c|c|c|c|c|c|}
\hline Polymer sample & $\begin{array}{c}\lambda \\
(\mathrm{s})\end{array}$ & $\begin{array}{c}\text { De } \\
(1)\end{array}$ & $\begin{array}{c}\text { mean du/dx } \\
(1 / \mathrm{s})\end{array}$ & $\frac{\eta_{\mathrm{E}, \mathrm{P}}}{\eta_{\mathrm{E}, \mathrm{U}}}$ & $\frac{\eta_{\mathrm{E}, \mathrm{U}, \max }}{3 \eta_{0}}$ \\
\hline LDPE 170A & 0.588 & 0.011 & 0.300 & 1.280 & 3.393 \\
\hline PE-A & 0.079 & 0.019 & 10.281 & 0.833 & 9.299 \\
\hline PE-B & 0.125 & 0.026 & 8.879 & 1.102 & 4.198 \\
\hline PE-C & 0.250 & 0.061 & 10.281 & 1.293 & 2.047 \\
\hline
\end{tabular}




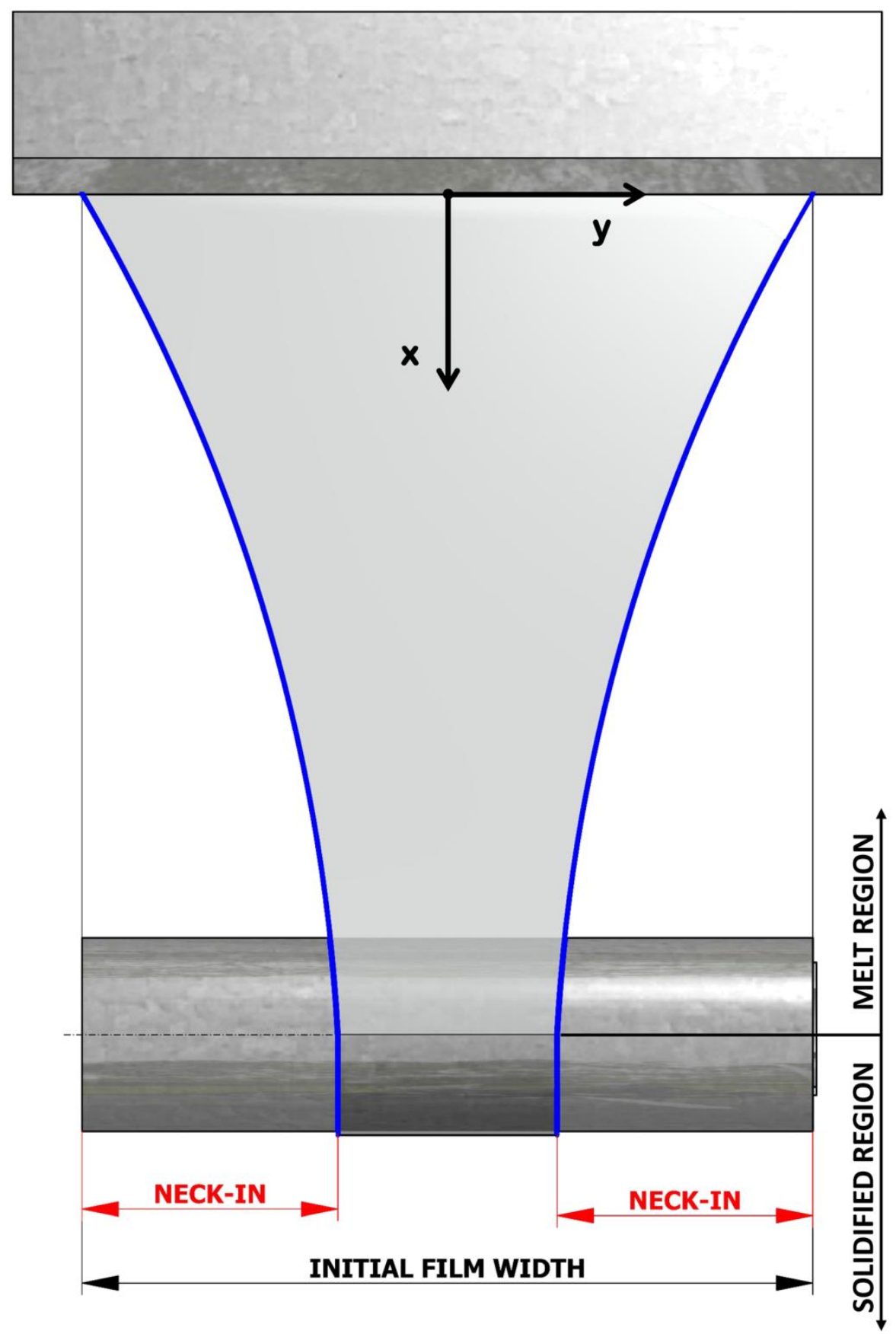

Figure 1. Neck-in phenomenon during the extrusion film casting process. 


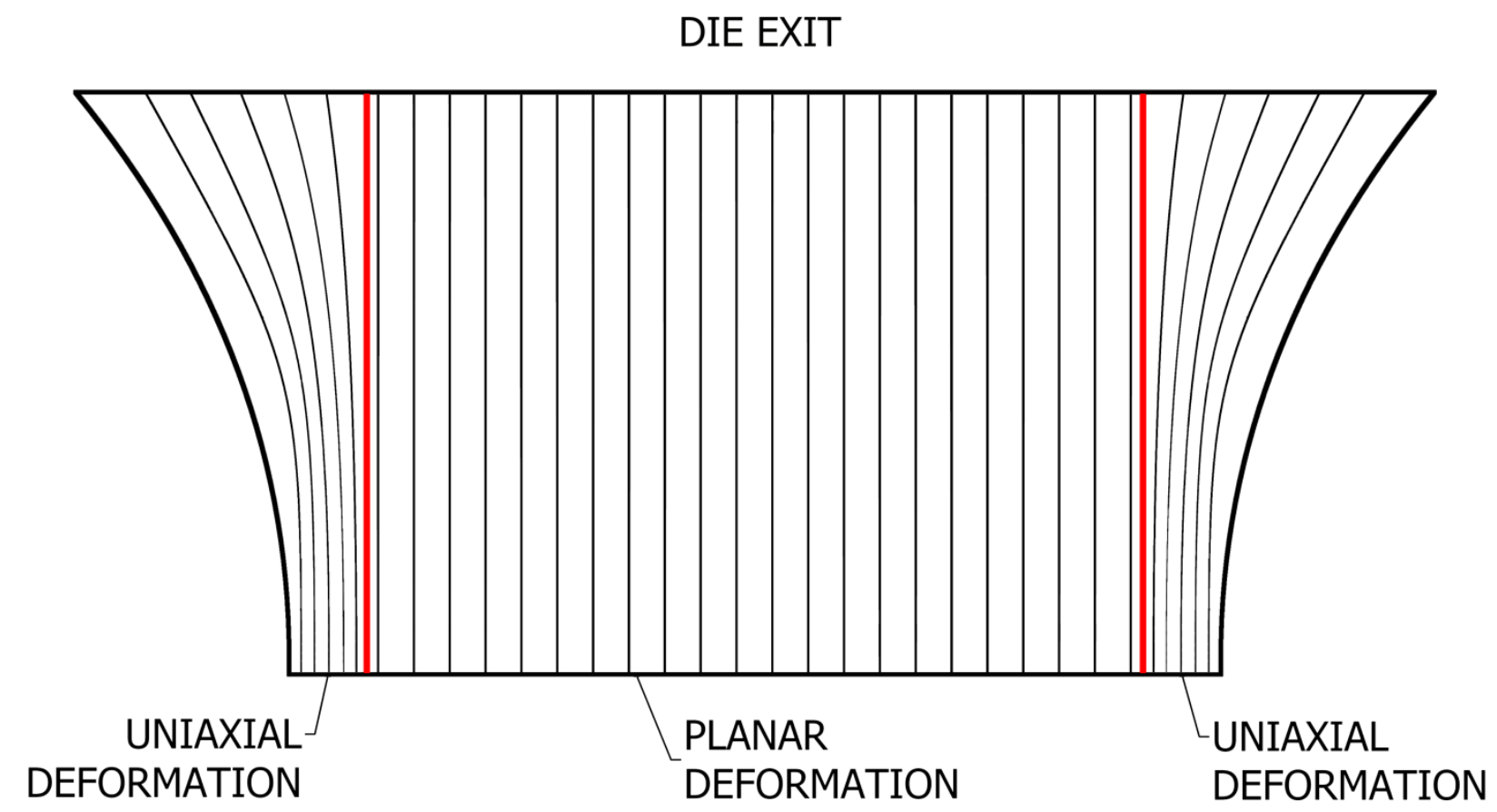

Figure 2. Visualization of planar and uniaxial extensional flows during the extrusion film casting process. 


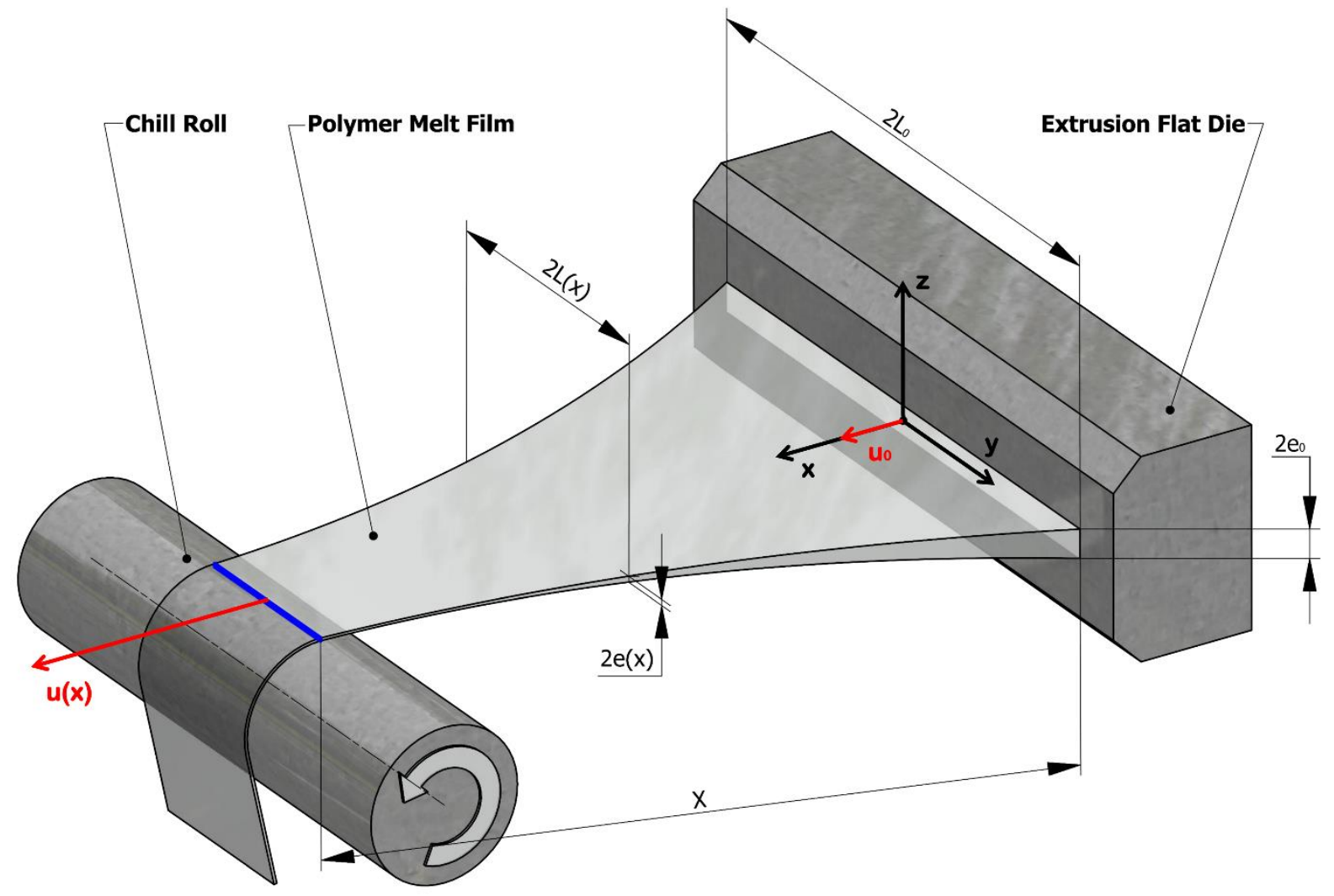

Figure 3. Schematic of the extrusion film casting process kinematic. 


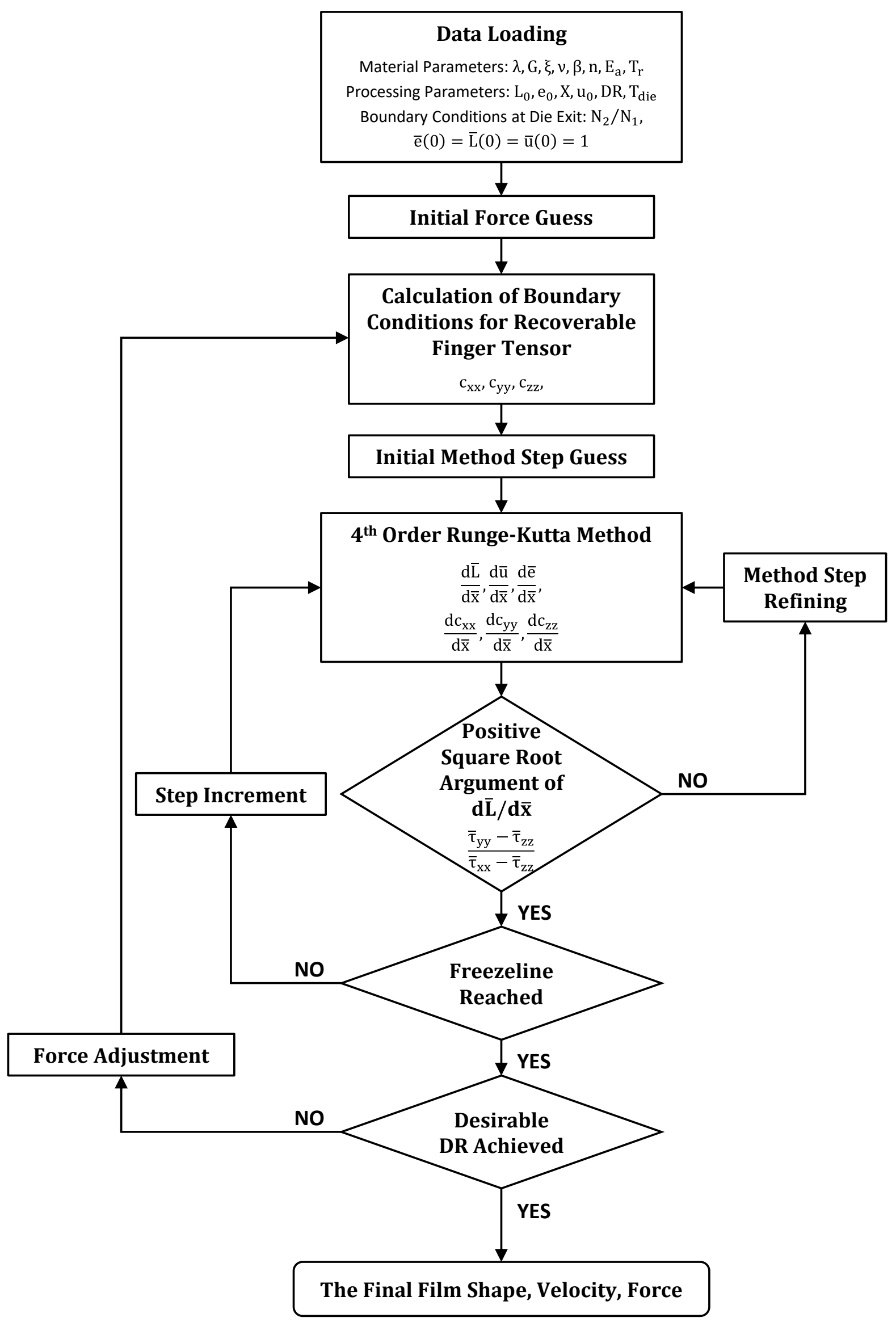

Figure 4. Iteration scheme for the utilized viscoelastic film casting model. 
5a)

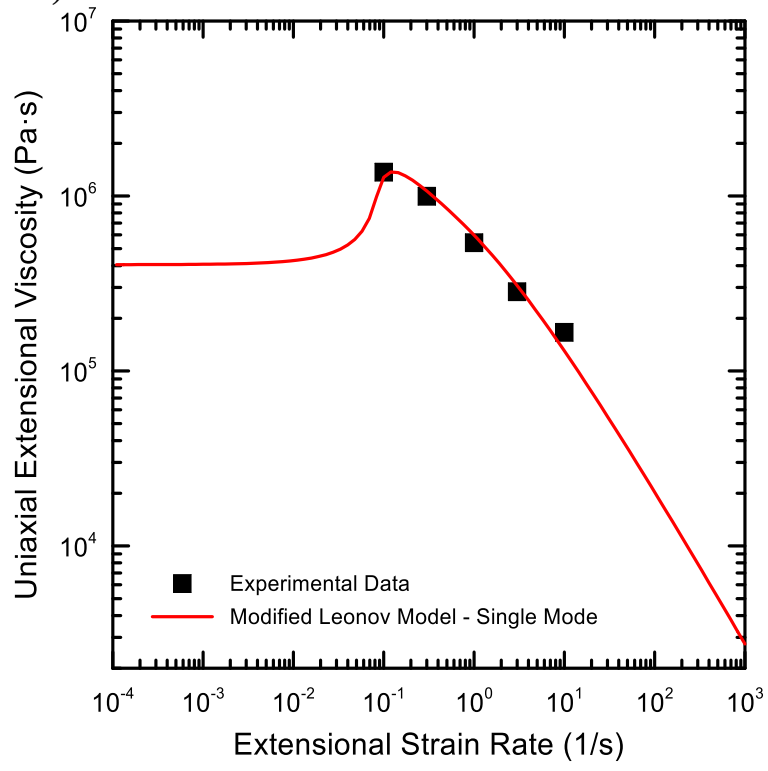

5c)

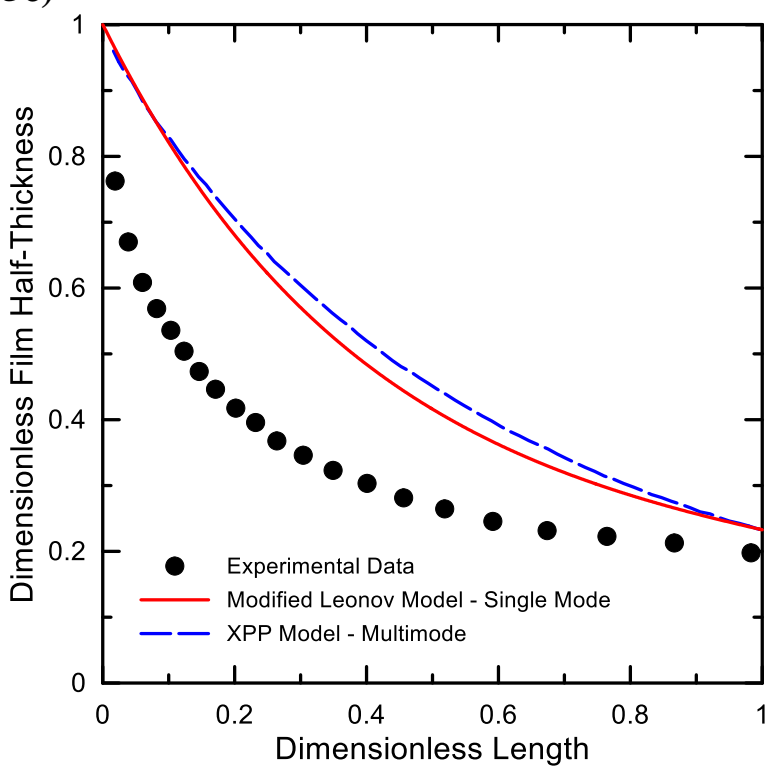

5b)

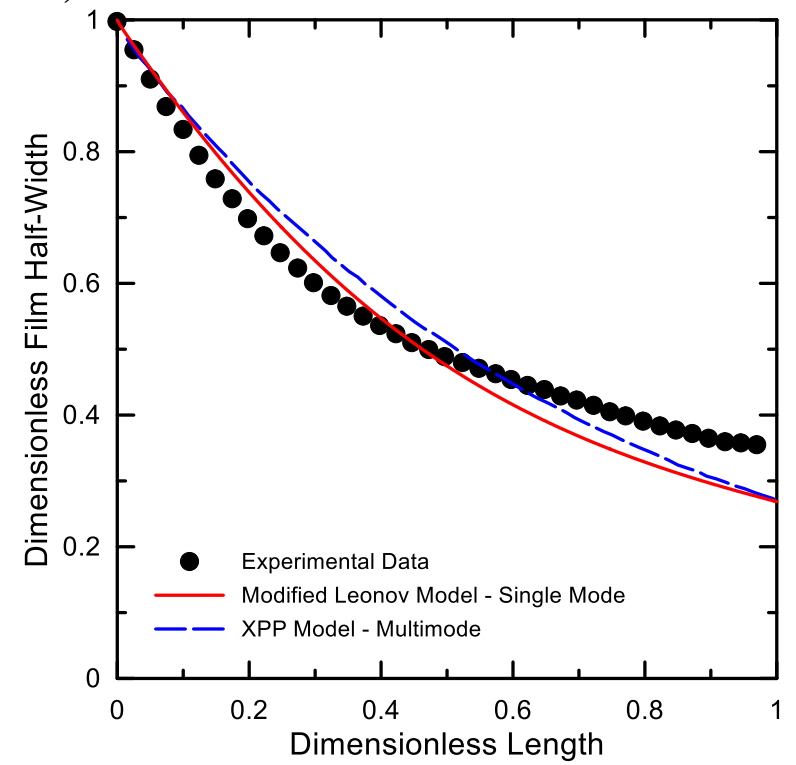

5d)

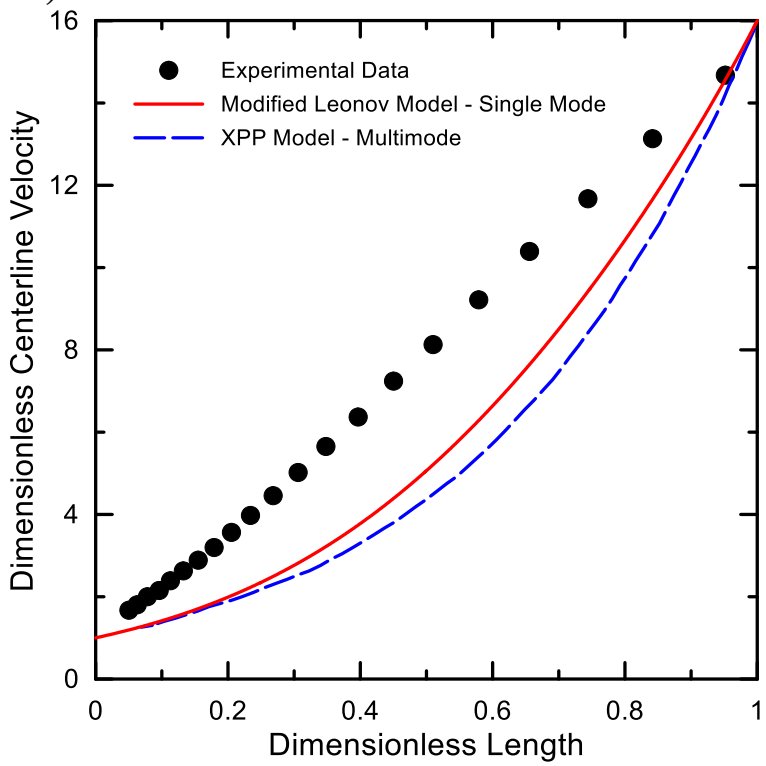

Figure 5. Comparison between experimental data for LDPE $170 \mathrm{~A}\left(\mathrm{~T}=150{ }^{\circ} \mathrm{C}\right)$ and given processing conditions ( $\mathrm{De}=0.011, \mathrm{DR}=16, \mathrm{X}=230 \mathrm{~mm}$ ) taken from the open literature [46] and corresponding model predictions considering that $-\mathrm{N}_{2} / \mathrm{N}_{1}=0.2$. 5a) LDPE $170 \mathrm{~A}$ extensional rheology, 5b) Film half-width profile between die and roll, 5c) Film halfthickness profile between die and roll, 5d) Velocity profile between die and roll. 

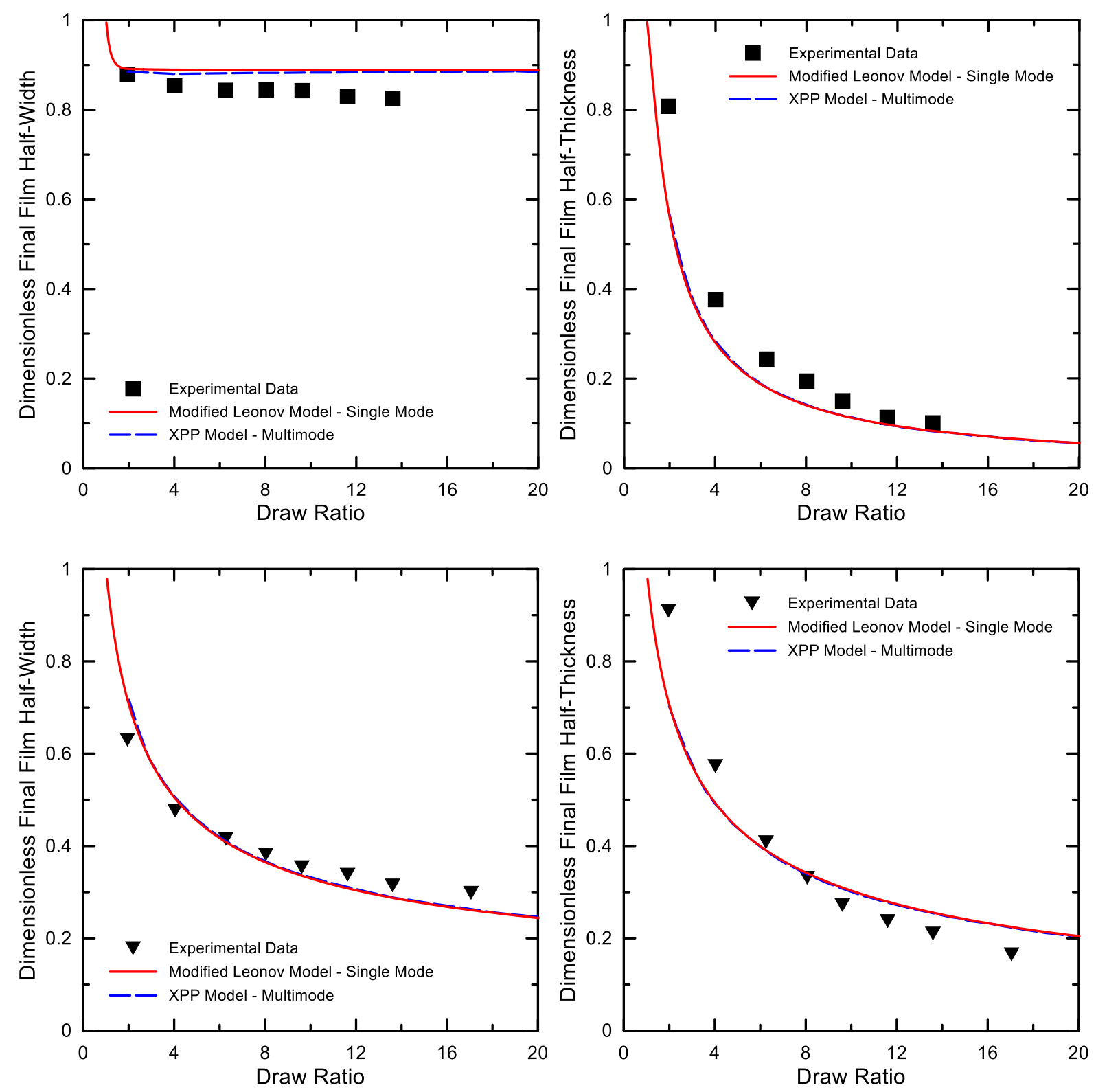

Figure 6. Comparison between experimental data for LDPE 170A taken from the open literature [45] for different Deborah numbers (top - De $=0.253, X=10 \mathrm{~mm}$, bottom $\mathrm{De}=0.011, \mathrm{X}=228 \mathrm{~mm}$ ) and corresponding model predictions considering that $-\mathrm{N}_{2} / \mathrm{N}_{1}=0.2$. Left - dimensionless final film half-width vs. draw ratio, Right - dimensionless final film half-thickness vs. draw ratio. 

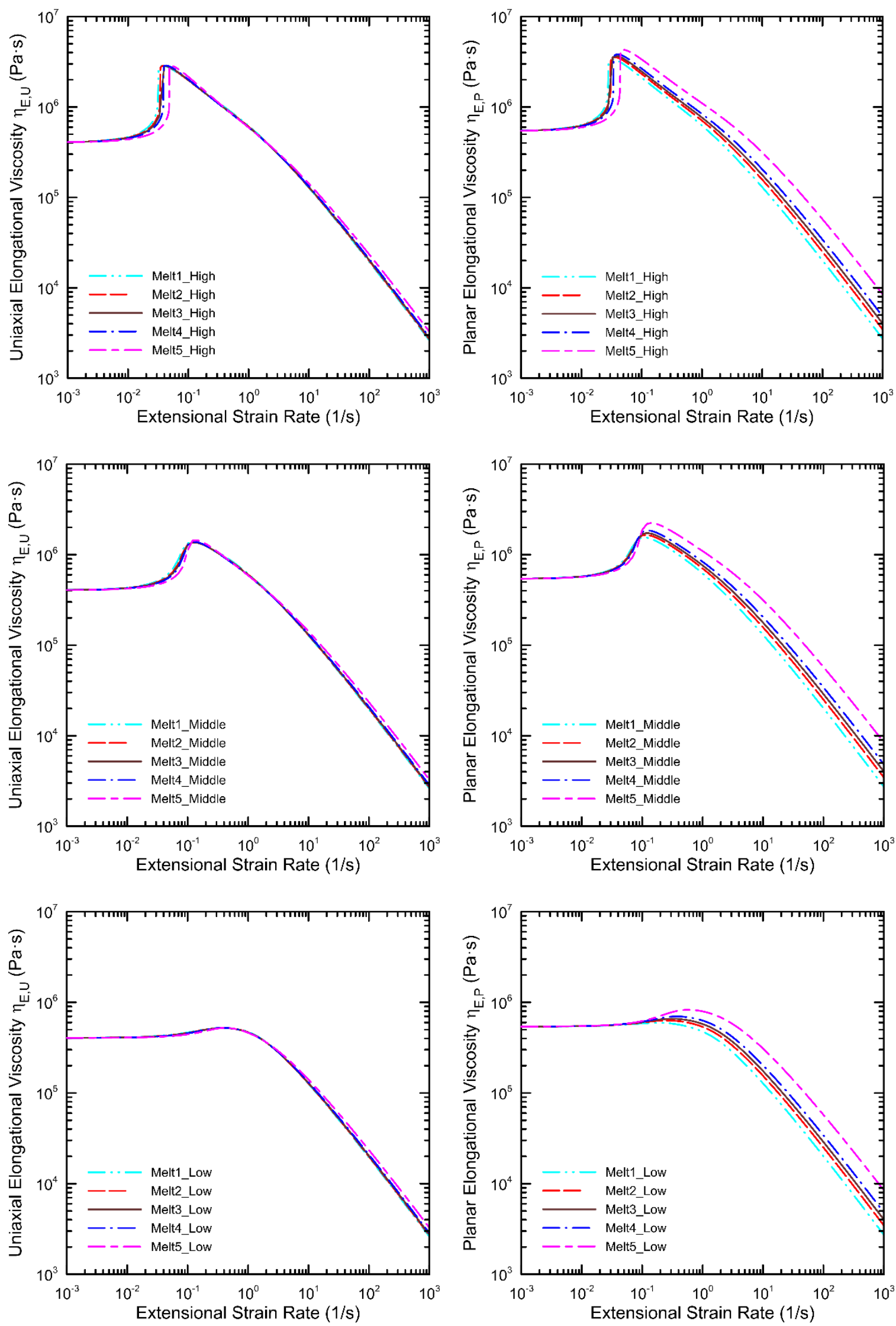

Figure 7. Uniaxial and planar extensional viscosities of different virtual polymer melts utilized in this work having high (top), medium (middle) and low (bottom) level of extensional strain hardening at $\mathrm{T}=130^{\circ} \mathrm{C}$. 

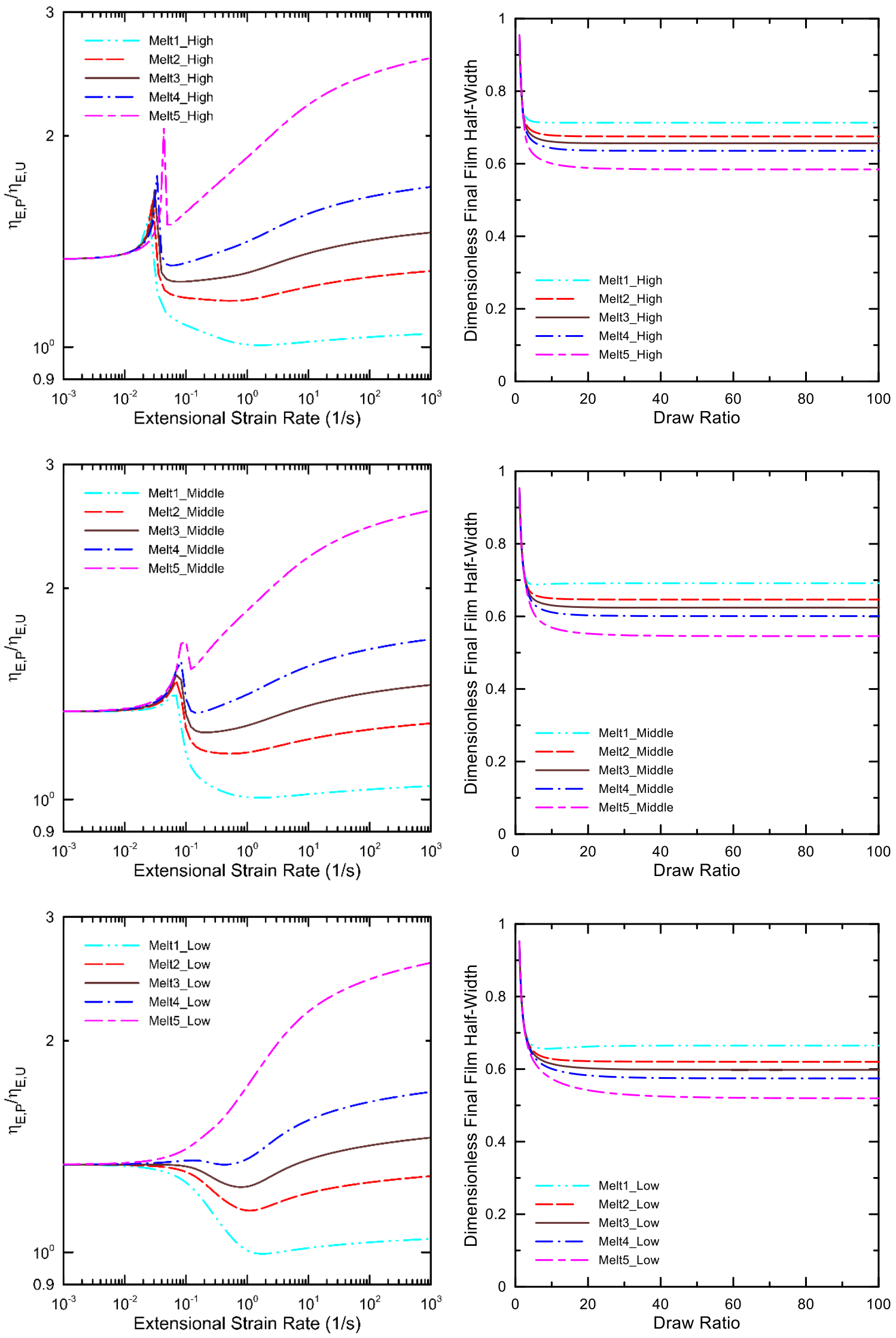

Figure 8. Effect of planar to uniaxial extensional viscosity ratio, $\eta_{\mathrm{E}, \mathrm{P}} / \eta_{\mathrm{E}, \mathrm{U}}$, on draw ratio dependent dimensionless final film half-width for high (top), medium (middle) and low (bottom) level of extensional strain hardening polymer melts considering that $-\mathrm{N}_{2} / \mathrm{N}_{1}=0.2$. 
9a)

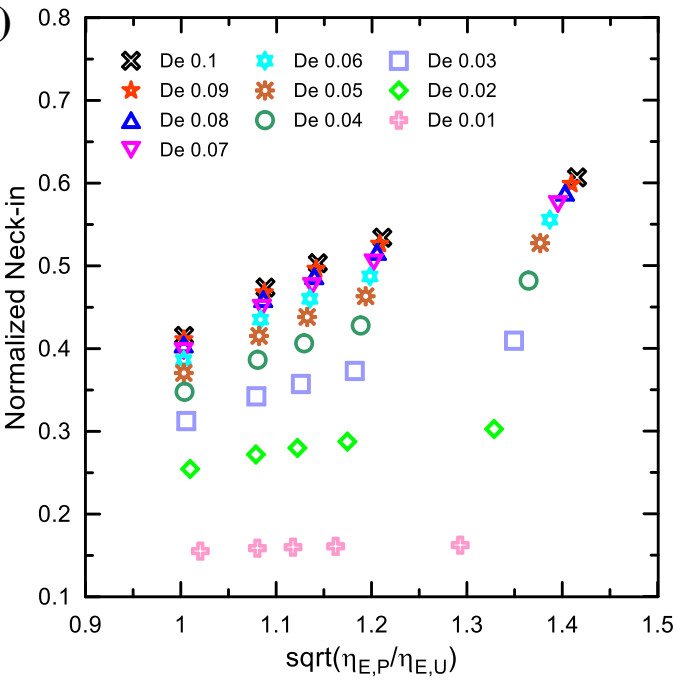

9b)

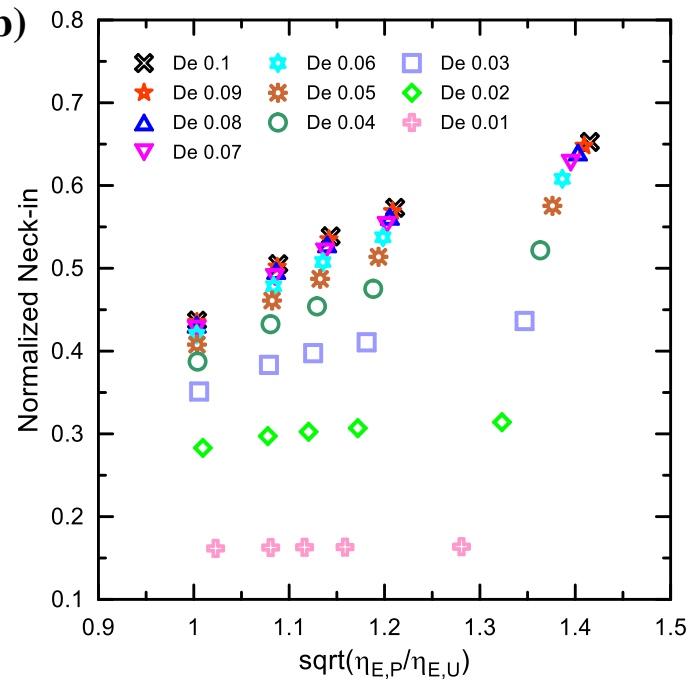

9d)

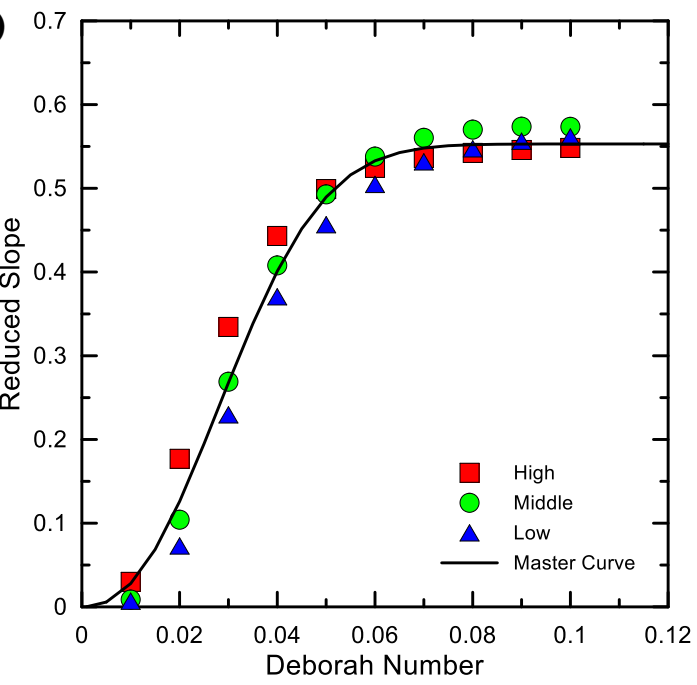

9e)

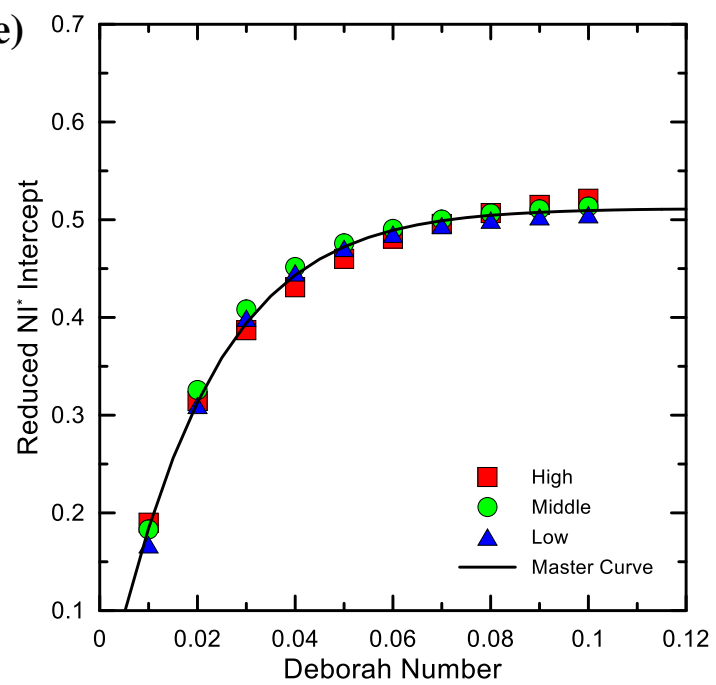

9c)

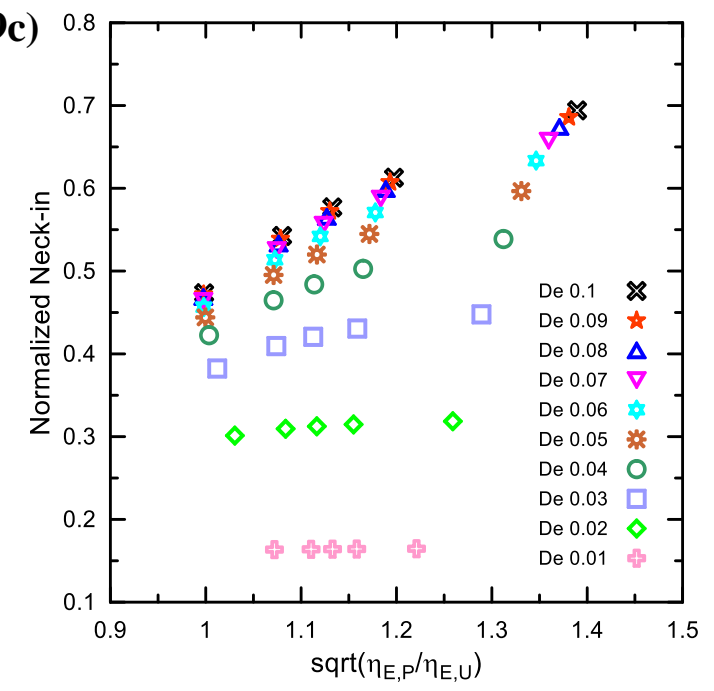

Figure 9. The effect of Deborah number and square root of planar to uniaxial extensional viscosity ratio, $\operatorname{sqrt}\left(\eta_{\mathrm{E}, \mathrm{P}} / \eta_{\mathrm{E}, \mathrm{U}}\right)$, on the normalized neck-in for high (9a) medium $(\mathbf{9 b})$ and low (9c) level of extensional strain hardening polymer melts considering that $-\mathrm{N}_{2} / \mathrm{N}_{1}=0.2$. Figure 9d and 9e shows Deborah number dependent reduced slope $k^{*}$ and the reduced $N I^{*}$ intercept $Q^{*}$ (both calculated from $k$ and $Q$ in Eq. 75), respectively, in comparison with the model fitting lines, which are given by Eqs. 76-77. 

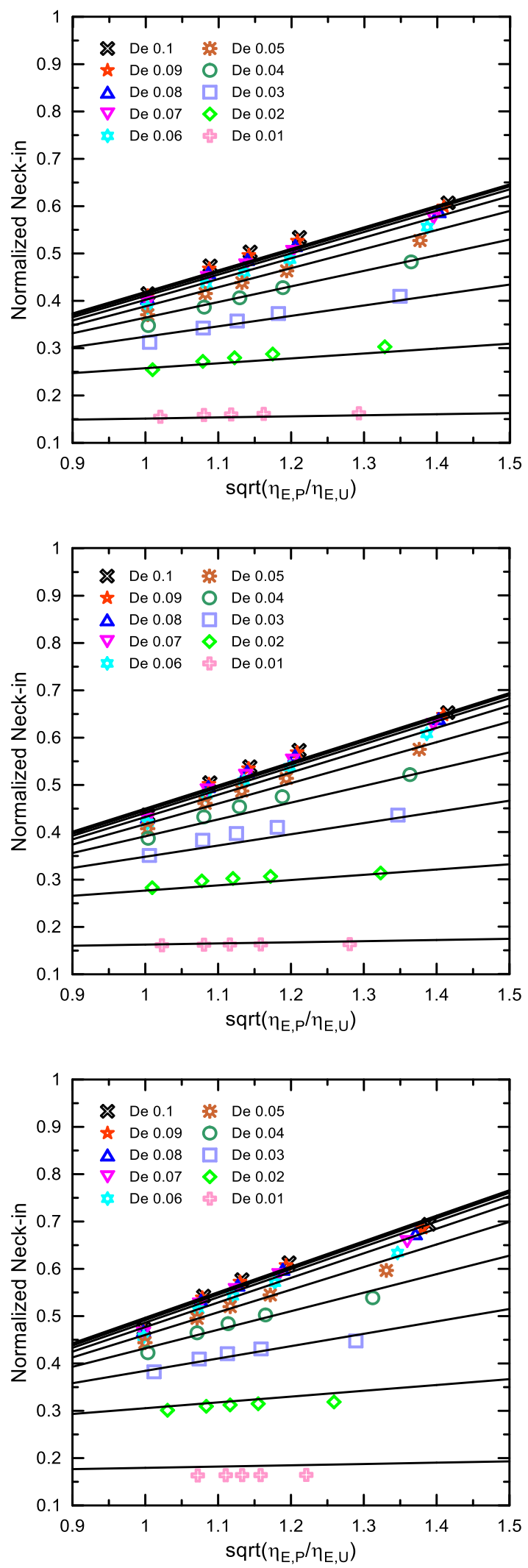

Figure 10. The effect of Deborah number on the normalized neck-in vs. planar to uniaxial extensional viscosity ratio for virtual polymer melts having high (top), medium (middle) and low (bottom) level of extensional strain hardening. Here, symbols and lines represent utilized viscoelastic 1D membrane model and simple approximate solution model (Eq. 80) predictions, respectively. 
11a)

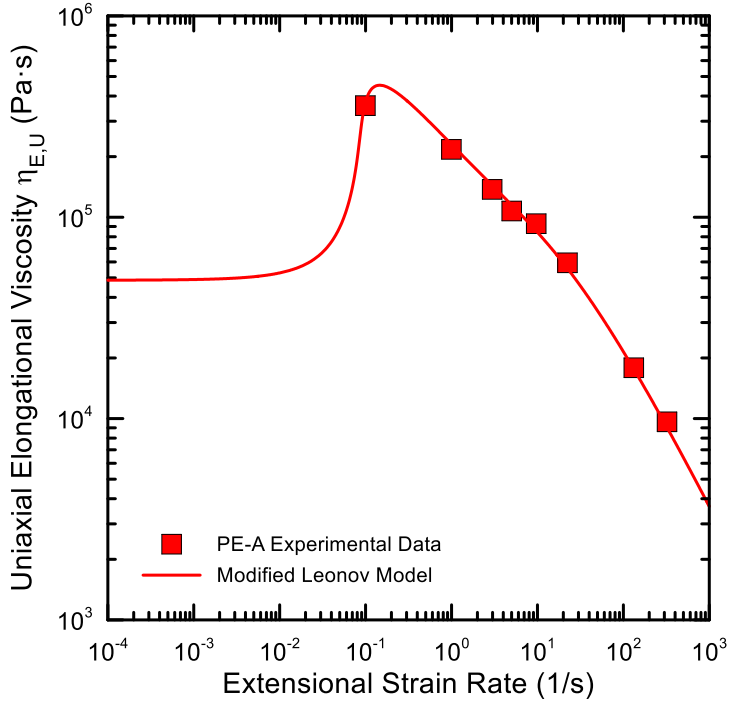

11b)

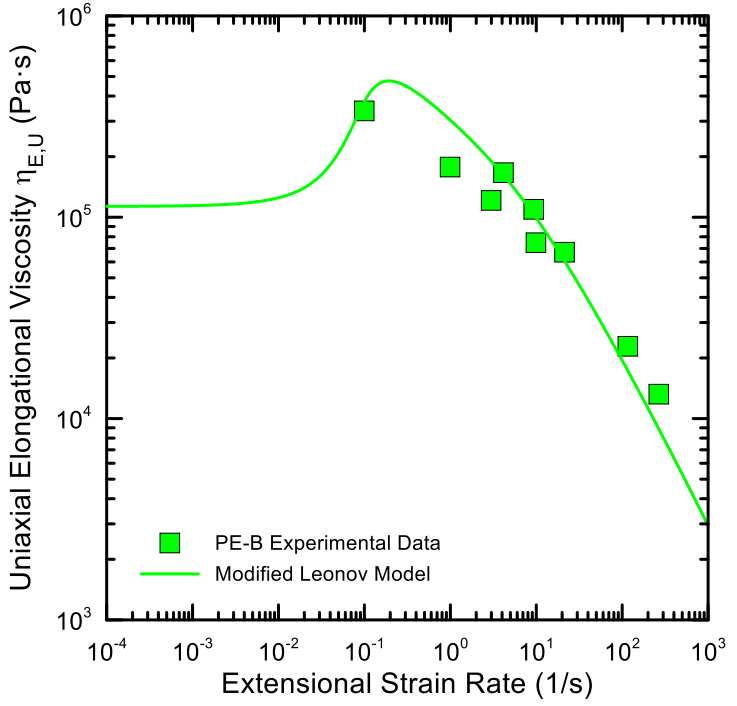

11c)

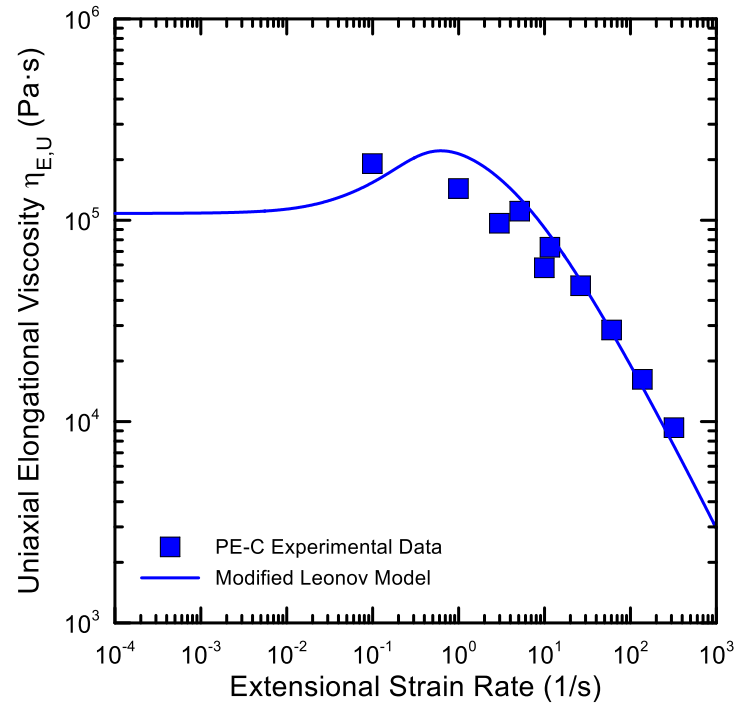

Figure 11. Comparison between experimentally determined deformation rate dependent uniaxial extensional viscosity data for different polymer samples at $130{ }^{\circ} \mathrm{C}$ taken from [26] and single mode modified Leonov model predictions. 11a) PE-A, 11b) PE-B, 11c) PE-C. 


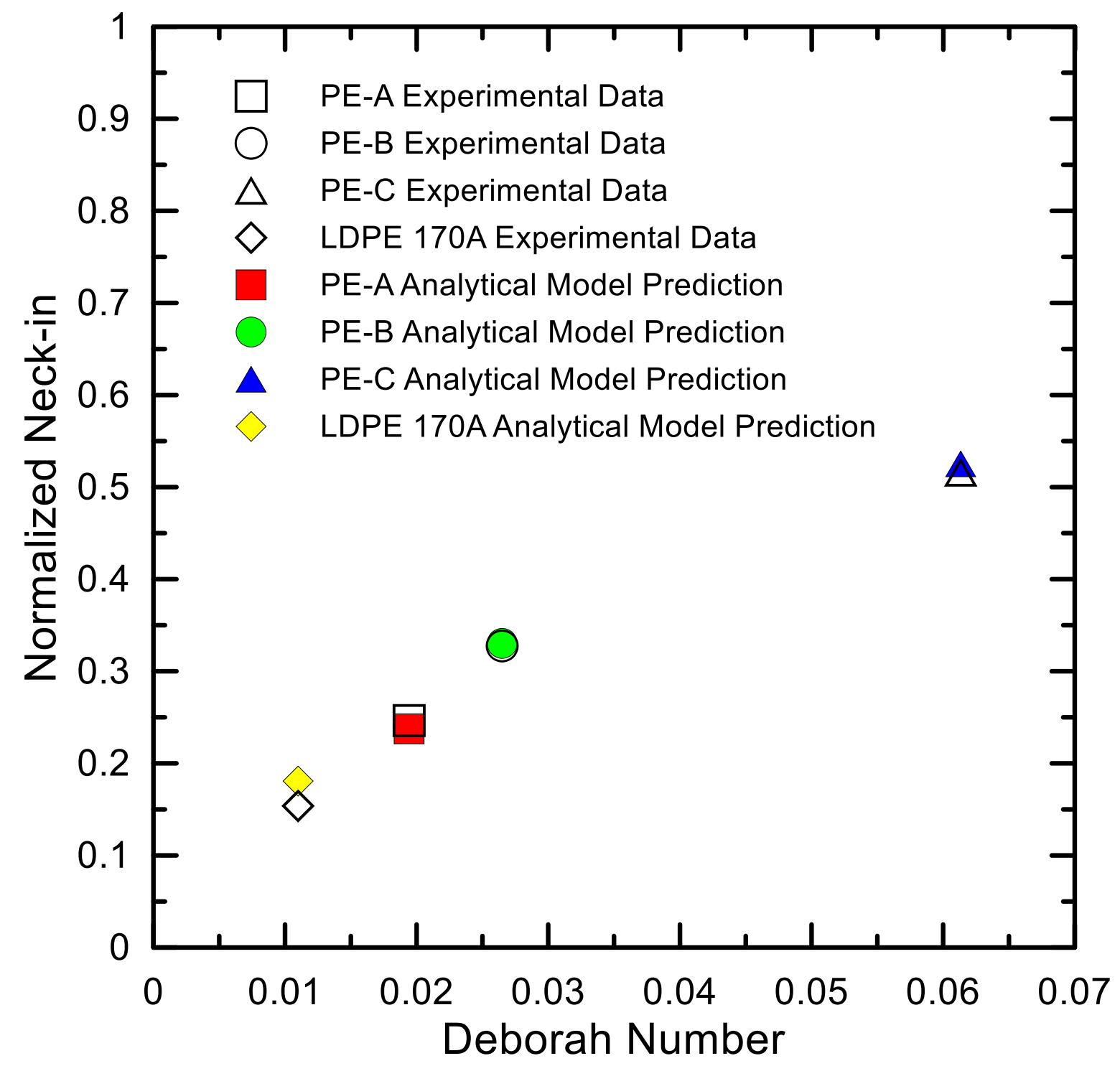

Figure 12. Normalized maximum and draw ratio independent neck-in value, $N I^{*}$, as the function of Deborah number for LDPE 170A, PE-A, PE-B and PE-C polymer samples for the processing conditions summarized in Table 8. Experimental data (taken from [45] and [26]) are represented here by the open symbols whereas the predictions of the proposed analytical model, Eq. 80, are given by the filled symbols. 